\title{
A 'Ghetto' of One's Own:
}

\section{Communal Violence, Residential Segregation and Group Education Outcomes in India}

\author{
Aarushi Kalra*
}

August 2021

\begin{abstract}
How does ethnic violence and subsequent segregation shape children's lives? Using exogenous variation in communal violence due to a Hindu nationalist campaign tour across India, I show that violence displaces Muslims to segregated neighbourhoods. Surprisingly, I find that post-event, Muslim primary education levels are higher in cities that were more susceptible to violence. For cohorts enrolling after the riots, the probability of attaining primary education decreases by $2.3 \%$ every 100 kilometres away from the campaign route. I exploit differences in the planned and actual route to show that this is due to greater spatial cohesion within communities threatened by violence.
\end{abstract}

*Department of Economics, Brown University, Providence, RI, 02906 (email: aarushi_kalra@brown.edu). I am grateful to Andrew Foster, Bryce Steinberg, John Friedman, Jesse Shapiro, Patrick Heller, David Weil, Jesse Bruhn, Alisa Tazhitdinova, Daniel Bjorkegren, Stelios Michalopoulos, Martin Mattsson, Naveen Bharathi, Diane Coffey and seminar participants at Brown University for invaluable comments. I thank Naman Garg, Jose Belmar, Marcela Mello, Joao Garcia, Giulia Buccione, Aastha Tyagi, Suvaid Yaseen, Harkirat Singh, and Saket Tiwari for their support. Disclosure: This research did not receive any specific grant from funding agencies in the public, commercial, or not-for-profit sectors. 
Ethnic inequality has serious economic ramifications across the Developing world (Alesina et al., 2016, 2020). Analyzing ethnic and inter-group inequality in India is especially important, as religious identity has gained a bigger role in expressions of conflict as well as inequality. Despite recent poverty reductions, Indian Muslims earn less than Hindu Dalits ${ }^{1}$, where the latter group is counted among the most historically disadvantaged communities in India. Muslim per capita incomes, on average, comprise only $68 \%$ of Dalit per capita incomes in Haryana, 69\% in Gujarat, and $87 \%$ in Maharashtra (NSSO, 2012). This paints a grim picture of the relative deprivation of this social group. Furthermore, only $14 \%$ of the Muslim population in India was likely to complete college education as opposed to $37 \%$ of Hindu upper castes (Jaffrelot and Kalaiyarasan, 2019).

My work investigates how religious conflict impacts educational outcomes of Muslims. Communal conflict not only exacerbates between-group income disparities (Esteban and Ray, 2011), it also leads to discriminatory practices and policies against the dominated group. This paper gauges the long run education choices that members of a threatened community make in the aftermath of violence. This is done using plausibly exogenous variation in communal violence due to a Hindu nationalist campaign tour across Indian states.

I find that communal violence is associated with improvement in early education outcomes of Muslim children who begin schooling after violent events. I take note of narrower education gap between Muslims and non-Muslims (as measured in various rounds of the NSS Employment-Unemployment Surveys between 1987 and 2012) in cities with a history of Hindu-Muslim conflict ${ }^{2}$. I provide descriptive evidence that stronger within-community ties, built on the aftermath of violence, may be driving this very surprising result. In lieu of micro-measures for within-community ties, I show high degree of association between cities segregated along religious lines, and cities exposed to communal tensions.

Identifying causal impact of communal violence is difficult because riots are more likely to occur in areas with rising Muslim incomes relative to Hindu incomes (Mitra and Ray, 2014). This is likely to generate omitted variable bias in the OLS relationship between

\footnotetext{
${ }^{1}$ The preferred political term for people belonging to the lowest caste in India, earlier characterised as "untouchable": https://en.wikipedia.org/wiki/Dalit.

${ }^{2}$ This is important because inter-group inequality and inter-generational economic mobility in India is best measured using data on education attainment (Asher et al., 2018), in the presence of measurement error in income data collected using survey methods.
} 
communal riots and education outcomes due to selection. To overcome this challenge, I leverage plausibly exogenous variation in riots that emerges from the planned path of a series of anti-Muslim campaign events. Known as the Ram Rath Yatra (henceforth, Yatra), this controversial campaign trail across several Indian states ${ }^{3}$, was organized by the Bhartiya Janata Party (henceforth, BJP) in 1990. During this campaign, many prominent leaders of the BJP planned to travel 10,000 kilometres (Mishra, 2015) to mobilize support for the demolition of a $16^{\text {th }}$ century Mosque in India ${ }^{4}$. This led to communal riots, majority of which took place on or very close to the campaign route (Engineer, 1991).

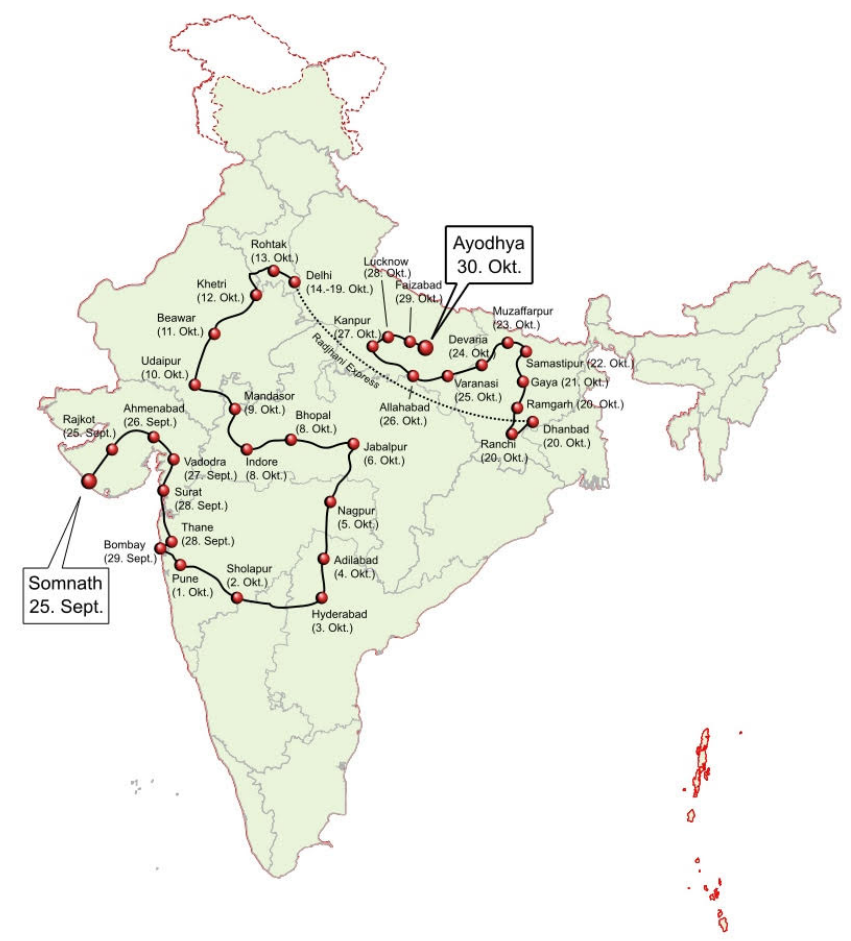

Figure 1: Plan of Rath Yatra Campaign Route, Rath Yatra (Source: David Ludden, India and South Asia: A Short History).

Following this empirical strategy, I find that Muslim cohorts starting school after the event in 1990 attain higher levels of primary education in cities that were more susceptible to rioting (and were closer to the campaign route). In particular, for Muslims in cohorts born

\footnotetext{
${ }^{3}$ Figure 1 shows the planned route of the campaign trail.

${ }^{4}$ The campaign commenced at the site of a famous temple in Somnath (Gujarat), and was to conclude in Ayodhya, the purported site of another temple allegedly destroyed by Mughal rulers.
} 
between 1986-90, the probability of attaining primary education fell by $0.23 \%$, with every 10 kilometres away from the campaign route.

To check the robustness of these results, I construct placebo tests by using difference in the planned and actual route of the Yatra. I claim that exposure to Yatra was exogenously determined, by assuming that the location of obstruction in the route is independent of outcome variables. This is granted by an unexpected impediment in the path of the campaign, when the leader of the movement (LK Advani) was arrested in the state of Bihar, before entering the destination state of Uttar Pradesh ${ }^{5}$. The placebo tests are successful, as these results do not hold with respect to the planned Yatra route in cities where the campaign did not enter.

I strengthen the reduced form results by demonstrating that Yatra indeed provides quasirandom variation in communal violence. I do not find differential patterns in the distribution of Muslim consumption expenditures, or in education infrastructure, pre and post-Yatra, across cities along the campaign route. However, I cannot rule out that the campaign was more likely to go to more populous cities. Therefore, I measure the effect of being closer to the Yatra route among cities with similar observable characteristics. I estimate the effect of violence on education by matching propensity scores at the individual level with continuous treatment (Hirano and Imbens, 2004). The treatment effect on early education remains statistically significant and negative for cohorts starting school after 1990.

I interrogate if residential segregation is a channel that led to improved early education outcomes among Muslim children who started school after violent events. I find a strong first stage relationship by way of negative correlation between distance from Yatra route and residential segregation. The dissimilarity index in 2013 falls by $0.2 \%$ with every 10 kilometres away from the route.

To check the validity of this correlation, I look for treatment effects on 'untreated' groups. Displacement on account of communal riots between Hindus and Muslims should not affect residential patterns of the Scheduled Caste (henceforth, SC) population, which has also been documented to live in segregated neighbourhoods in Indian cities (Bharathi et al., 2018). Therefore, SCs are being held as the untreated group. I am able to demonstrate

\footnotetext{
${ }^{5}$ See Section 1.1 for background details.
} 
that the continuous treatment, by way of distance from the Yatra route, is uncorrelated with segregation of SC populations. I also check for treatment effects in states that were not exposed to the campaign (controlling for spillovers), and do not find any correlation of the treatment with segregation of Muslims in these states.

I follow Abdulkadiroğlu et al. (2014) in order to estimate the causal effect of neighbourhood on early education outcomes of Muslims. I impose weak assumptions on the direction of bias induced by factors (other than segregation induced by displacement), that relate to communal violence and potentially bias estimates of the neighbourhood effects. I demonstrate that neighbourhood effects on Muslim education outcomes continue to remain positive, when other violence related factors in the education production function are argued to impact Muslim education outcomes negatively.

Finally, I offer a discussion of possible mechanisms that may be driving the surprising effect of communal violence and segregation on Muslim education outcomes. I hypothesize that strong ties (Granovetter, 1973) within a community provide role models and resources to pursue primary education. This hypothesis is supported by qualitative evidence in Jaffrelot and Gayer (2012), which shows that members of Muslim enclaves who were segregated by communal violence in Gujarat, eventually achieved higher socio-economic status. This was true despite the conspicuously absent public provision of welfare for this community, and because communities are very tightly knit in the aftermath of violence, as members support each other to rebuild businesses and incomes.

This paper speaks to four strands of literature in Economics: one deals with measurement, causes and effects of ethnic or inter-group inequality; while the other relates to the role of ethnic violence in determining socio-economic outcomes. In interrogating channels through which inter-group violence impacts education outcomes, my work is, thirdly, related to literature investigating the relationship between residential segregation of historically disadvantaged groups and their economic outcomes. Finally, this paper picks up on the recent literature on human capital formation among Muslim communities.

First, this paper extends the vast and rapidly growing literature on inter-group inequality and inter-generational economic mobility (Chetty et al., 2014) to developing countries. Alesina et al. (2016) measure consequences of ethnic inequality across African countries, 
whereas Sethi and Somanathan (2010) investigate the relationship between group identities and mobility for the Scheduled Castes and Scheduled Tribes in India. In particular, my work is especially relevant in contexts where religion is key in the process of identity formation, and is closely tied with the work of Alesina et al. (2020) and Asher et al. (2018), who study the relationship of Muslim identity with educational mobility in Africa and India, respectively. This paper contributes to this literature by investigating the causes for differences in educational attainment across religious groups, and the role of conflict herein.

Second, this work fits into the literature on the economics of ethnic conflict. Mitra and Ray (2014) interrogate the correlates of communal riots and verify the hypothesis that a relative increase in Muslim income or consumption is associated with an increase in the probability of a riot. Iyer and Shrivastava (2015) as well as Blakeslee (2018) use Instrumental Variable approaches to show that Hindu-Muslim riots increase the vote share of the BJP in elections that follow such rioting. I borrow Blakeslee's (2018) assignment of electoral wards to the Yatra route (in Figure 2) to construct my continuous treatment, i.e. distance of a city from the Yatra route. Field et al. (2008) consider the case of communal violence in Ahemdabad (Gujarat), and find that riots were more likely to break out in more integrated neighbourhoods. They also hypothesized, albeit did not test, that residential segregation was likely to increase after the riots. I bring evidence to test this hypothesis, while looking at the impact of violence on a broader range of outcome variables.

Third, this analysis deals with the literature on residential segregation and socio-economic outcomes of marginalized groups in the Indian context. Chetty and Hendren (2018) analyze the effect of neighbourhoods on child development across races in the US. This is done, in part, by exploiting exogenous displacement shocks, and therefore, ties closely with my empirical strategy. Susewind (2017) provides a description of segregation across religious lines in India using electorate rolls at the ward level for 11 cities $^{6}$. However, Bharathi et al. (2018) demonstrates that ward level variation does not fully capture concentration of social groups in various parts of a city, and therefore, document segregation along caste lines at neighbourhood levels.

\footnotetext{
${ }^{6} \mathrm{~A}$ ward is a local administrative unit of a city, with an average population of 1,500 to 6,000 for small statutory towns, and 30,000 to 200,000 for larger metropolitan cities (Prasad, 2006). It is therefore, much larger than an enumeration block (which measures a neighbourhood in this paper) with population of 650 to 700 (MRD and MHUPA, 2011).
} 


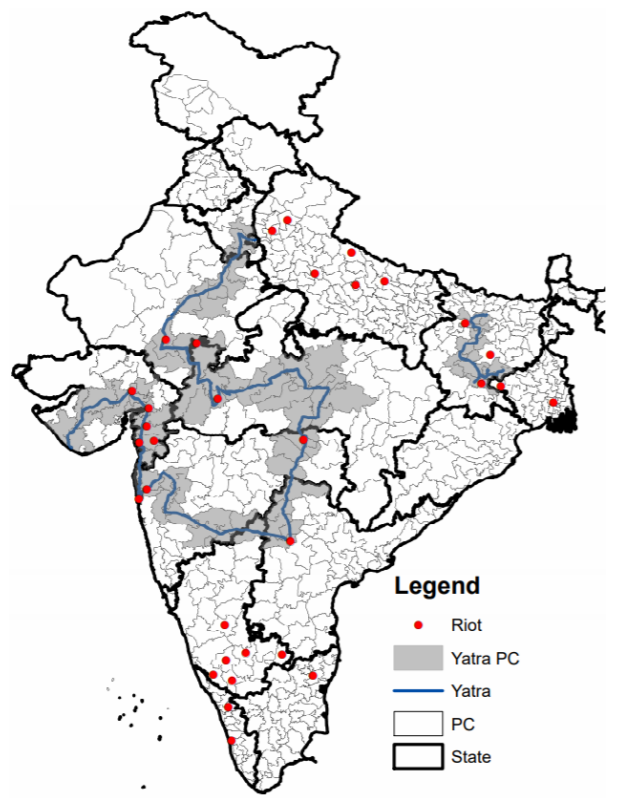

Figure 2: Actual campaign route, Rath Yatra (Source: Blakeslee (2018))

The literature on residential segregation in India has mainly focused on segregation along caste, and not religious lines ${ }^{7}$. Most recently, Adukia et al. (2019) use neighbourhood and religious identifiers in the Economic Census to provide descriptive evidence of residential segregation along communal lines. Mine is the first attempt to provide causal estimates of neighbourhood effects on long-term education outcomes among Muslims.

Finally, there is sprouting interest in the positive effects of ethnic enclaves in Developing Countries. Despite lower wealth, consumption, educational attainment, and access to state services (Jaffrelot and Kalaiyarasan, 2019), Muslims exhibit higher human capital accumulation in early childhood (Bhalotra et al., 2010). Geruso and Spears (2018) link religious composition of neighbourhoods with lower infant mortality among Muslims, through the channel of sanitation. Meyersson (2014) shows that women's political participation as well as secular high school education rates increased in Turkish municipalities where Islamic parties came to power, due to strong within-community ties. This paper links segregated

\footnotetext{
${ }^{7}$ This is primarily due to the fact that most government sources of data do not share information at the neighbourhood level, to ensure safety of historically marginalised groups. Neighbourhood level data (electoral rolls, for instance) on Muslims is documented to make the community more vulnerable in the event of a riot (Jaffrelot and Gayer, 2012).
} 
Muslim enclaves with higher early education attainment for Muslims in India.

The rest of the paper is organized as follows: Section 1 describes the data sources along with a brief background of the Yatra, Section 2 describes the Empirical Strategy, Section 3 describes the reduced form results and explores the channels driving them, Section 4 demonstrates a range of robustness checks, Section 5 discusses the results along with necessary caveats and concludes.

\section{Data}

In this section, I set the socio-political context and provide a broad overview of the background. I also provide a detailed description of the employed data sources.

\subsection{Ram Rath Yatra Route}

\section{Background}

The Ram Rath Yatra rally was part of the Ram Janmabhoomi ('birthplace of Ram') movement. The goal of this movement was the construction of a temple for the mythical king Ram at his legendary birthplace in Ayodhaya, Uttar Pradesh ${ }^{8}$. According to supporters of this campaign, the original temple at his birthplace was destroyed by the Mughal ruler Babur, who in its place built a mosque, Babri Masjid in 1527 (Rashid and Venkataraman, 2019). These claims are made based on archaeological evidence that has been challenged by independent historians and archaeologists (Gopal et al., 1990).

This movement gained importance on the Indian political landscape due to various factors including,

- The breaking out of an armed rebellion against the Indian state in Muslim-majority region of Kashmir, claiming more than tens of thousands of lives ${ }^{9}$

\footnotetext{
${ }^{8}$ This goal was achieved on August 5, 2020 when Prime Minister Narendra Modi laid the foundation stone of the Ram Temple after a long legal battle. https://www.bbc.com/news/world-asia-india-53577942.

${ }^{9}$ https://www.bbc.com/news/10537286.
} 
- The Mandal Commission award of affirmative action to backward castes threatened the position of upper-caste Hindus (Balagopal, 1990). In 1980, the Socially and Economically Backward Classes Commission's report recommended that members of Other Backward Classes (OBC) be granted reservations in $27 \%$ of jobs under public sector undertakings

- The Shah Bano case in the Supreme Court of India, which was a controversial maintenance lawsuit where the Supreme Court delivered a judgment favouring maintenance given to an aggrieved divorced Muslim woman. The Congress government enacted a law, shifting the onus of maintaining her to her relatives or the Waqf Board, solidifying the perception that the Congress party favoured Muslims (Pathak and Rajan, 1989)

These political factors culminated into hostility between the two communities, and led to Hindus feeling threatened in a country where they constitute the majority population. The objective of the campaign was to promote a unitary Hindu identity transcending the divisive caste system. This identity was perceived to be threatened on account of the Muslim community and upward mobility of backward castes (Jaffrelot, 2010).

The Yatra commenced on September 25, 1990, at the site of a famous temple in Somnath (Gujarat), and was to conclude in Ayodhya (Uttar Pradesh), the purported site of another temple allegedly destroyed by Mughal rulers. Political rallies and religious processions were held along the path of the route, with Hindu activists greeting and cheering the campaign wherever it went ${ }^{10}$.

\section{The Route}

Blakeslee (2018) constructed data on the route of the Yatra using daily accounts from the The Times of India, one of the major national newspapers in India. Using these journalistic accounts along with GIS maps of Parliamentary constituencies, the road network and builtup areas, he determines the constituencies through which the Yatra had actually passed.

I use Figure 2 to plot the Yatra route on GIS maps and then compute the distance of the route from sample cities, in kilometres. This is done for eight states where the Yatra

\footnotetext{
${ }^{10}$ In his film In the name of God, director Anand Patwardhan captured the site of thousands of people assembling to welcome the arrival of the Yatra in various cities, thus deeply polarizing the political environment.
} 
was planned to enter: namely Gujarat, Maharashtra, Andhra Pradesh, Madhya Pradesh, Rajasthan, Haryana, Bihar and Uttar Pradesh.

Note that the route does not enter Uttar Pradesh (UP), whereas Ayodhya (the destination of the route) is in UP. This was on account of Bihar government's decision to arrest LK Advani, the leader of this campaign, before they entered $\mathrm{UP}^{11}$. This is key for my identification strategy as I calibrate distance of a city in UP from planned route, using Figure 1 and GIS maps, to perform placebo tests.

\subsection{Riots}

A number of Hindu-Muslim riots erupted along the route of the Yatra. On November 1, 1990 (a day after the planned culmination of Yatra), riots broke out in a number of places, and curfew was enacted in at least 30 districts (Engineer, 1991). Of the 64 Hindu-Muslim riots which took place between 1990-91, 35 occurred during the 6 weeks surrounding the Yatra, 11 of which were in constituencies through which it passed (Blakeslee, 2018).

In Figure 3, I use Varshney and Wilkinson (2006) data set on communal violence in India, to plot the count of riots (in the aftermath of the Yatra) as a function of distance from Yatra route. It is clearly demonstrated that cities closer to the route were much more susceptible to rioting, than cities that were farther away.

\footnotetext{
${ }^{11}$ On October 23, LK Advani, one of the most powerful leaders of the BJP who led the Yatra, was arrested in Bihar's Samastipur district on the orders of then Chief Minister Lalu Yadav to prevent him from proceeding to Ayodhya.
} 


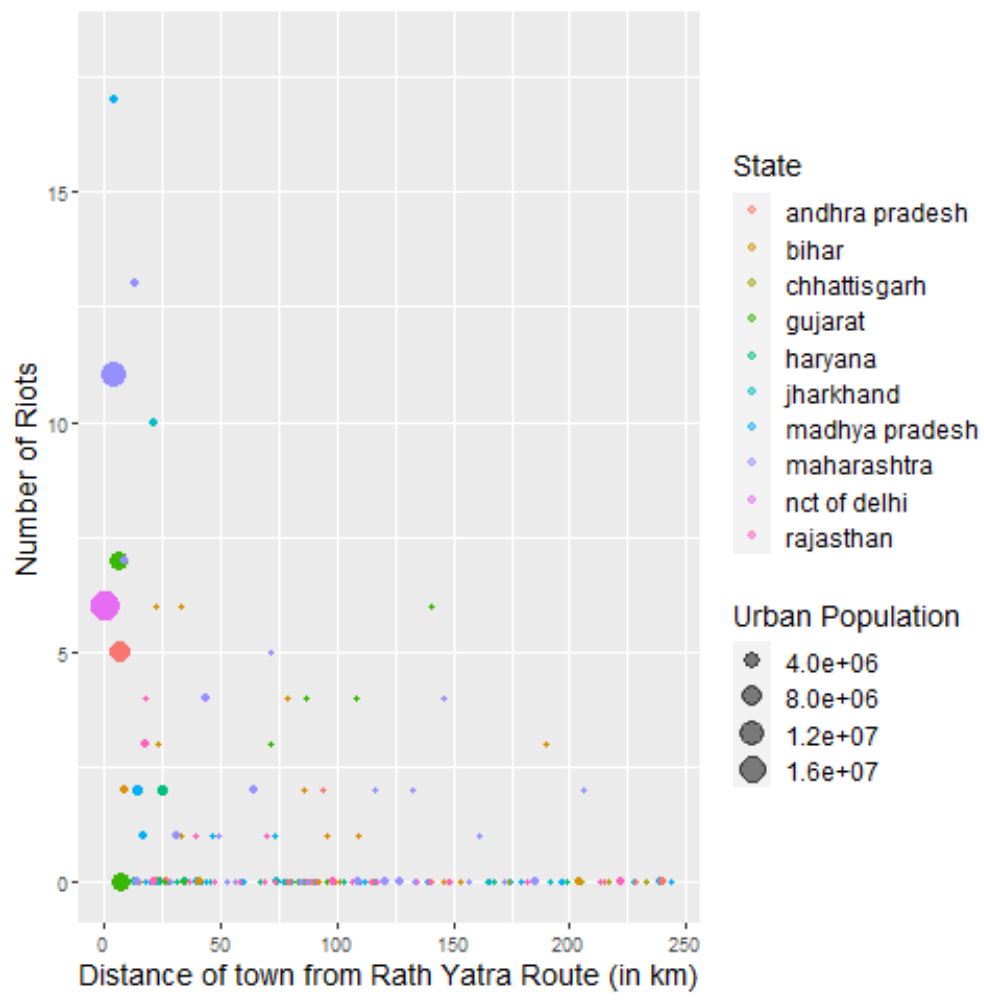

Figure 3: Number of Riots (1990-93) by Distance from Yatra route

These date provide comprehensive information on all Hindu-Muslim riots reported in a newspaper of record (The Times of India, Bombay edition), from January 1950 through December 1995. The data consists of information about the location as well as injuries and deaths. Of particular interest are the riots between 1990 (start of the Yatra campaign) until 1993 (after the ultimate demolition of Babri Masjid in December 1992). I geocode this data $^{12}$ to match with town level indices constructed using the Economic and Population Censuses of India and SEDAC (2011).

\subsection{Education Outcomes}

I access demographic information of individuals in sample households-level of education, gender and age- from the National Sample Survey Organization's Employment Unemploy-

\footnotetext{
${ }^{12}$ courtesy, Naman Garg for geocoding cities in Varshney and Wilkinson (2006).
} 
ment Surveys (NSS-EUS, thick rounds between 43 (NSSO, 1988) to 68 (NSSO, 2012)). I obtain household level attributes like religion, social group, and consumption level from the same data source. I normalize current consumption and wages (in Rupees), setting 1983 as the base year, using disinflation factors from Consumer Price Index for Industrial Workers series (Reserve Bank of India, 2018).

I link urban centres of districts in the NSS data with cities in the Economic and Population Censuses, and use district urban averages as proxies for city-level averages, following Greenstone and Hanna (2014). Since district boundaries have changed over time (Somanathan and Kumar, 2009), I use district keys from NSS-EUS round 43, held in $1987^{13}$ to harmonize administrative boundaries over the sample period ${ }^{14}$.

I divide the sample of Muslim and Non-Muslim individuals (after dropping members of Scheduled Castes (SC) and Scheduled Tribes (ST)) into six cohorts: (1) Born before 1950, (2) Born 1951-60, (3) Born 1961-70, (4) Born 1971-80, (5) Born 1981-90 and (6) Born between 1991-96. Figure 4 shows trends in educational attainment within the two groups of interest: Muslims and Non-Muslims.
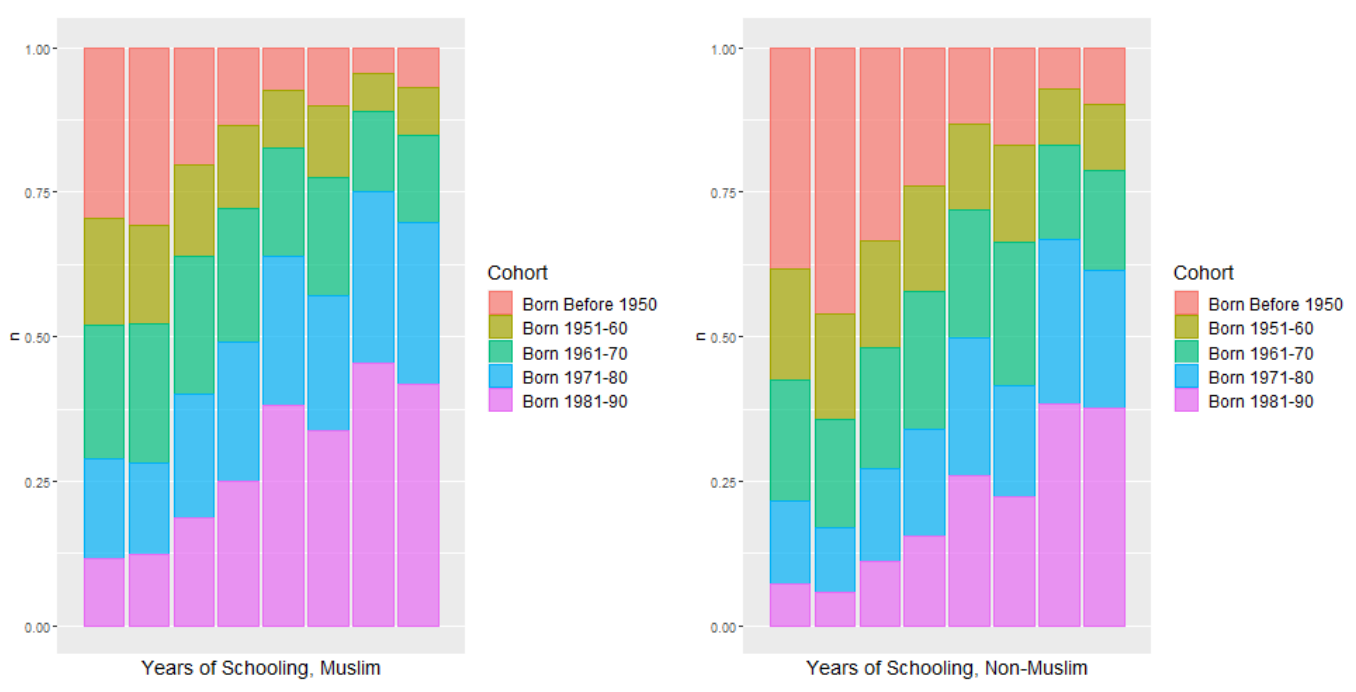

Figure 4: Within group variation in levels of education, by cohort

\footnotetext{
${ }^{13}$ courtesy Bryce Steinberg, for sharing district mappings across NSS rounds

${ }^{14}$ The resulting imprecision in matching leads to considerable noise. See Harari (2020) for a detailed treatment of matching Indian cities in Census and NSS data
} 
I describe the education gap between Hindus and Muslims in sample states in Table 1. It is worth noting that mean levels of education are systematically lower among Muslims for all the cohorts.

\begin{tabular}{cccccccccccc}
\hline Cohort Born & \multicolumn{2}{c}{ Before 1950 } & \multicolumn{2}{c}{$1951-60$} & \multicolumn{2}{c}{$1961-70$} & \multicolumn{2}{c}{$1971-80$} & \multicolumn{2}{c}{$1981-90$} \\
\hline Whether Muslim & No & Yes & No & Yes & No & Yes & No & Yes & No & Yes \\
\hline Illiterate & 30.02864 & 50.79830 & 18.09566 & 37.71874 & 14.84766 & 31.27104 & 10.33762 & 22.08000 & 5.42100 & 13.48787 \\
Primary School & 58.19958 & 33.95423 & 74.38935 & 49.07731 & 78.89624 & 55.72391 & 84.90503 & 67.36000 & 91.14260 & 78.31379 \\
Middle School & 45.62408 & 21.78020 & 62.85213 & 33.88482 & 67.63743 & 39.39394 & 75.87518 & 51.18000 & 83.33450 & 63.22384 \\
Secondary School & 35.22632 & 14.18308 & 48.84306 & 21.36494 & 51.97007 & 24.10564 & 58.68956 & 31.00000 & 63.68395 & 36.68666 \\
College & 14.539067 & 4.350718 & 21.766857 & 6.745148 & 21.591673 & 7.070707 & 26.033095 & 8.640000 & 21.041856 & 7.106417 \\
\hline
\end{tabular}

Table 1: Across group variation in level of schooling, by cohort

Furthermore, I slice the cohorts constructed by birth years into five-year intervals, to highlight the correlation between year of birth relative to the year 1990, and educational attainment. I expect educational outcomes for Muslims born between 1975 and 1985 to be directly disrupted by Yatra, as this cohort was still in school at the time of violence. Of particular interest are the education outcomes of the children born between 1985 and 1990, as they enrolled in school after the violence and subsequent displacement.

\subsection{Segregation}

I measure segregation using the dissimilarity index (Massey, 1990). Residential segregation, for some city $c$, is measured as:

$$
d_{c}=\frac{1}{2} \sum_{i}\left|\frac{m_{i c}}{M_{c}}-\frac{h_{i c}}{H_{c}}\right|
$$

where, $m_{i c}$ is the Muslim population in city $c$ in neighbourhood $i, M_{c}$ is the total population of Muslims in city $c, h_{i c}$ is the non-Muslim population in city $c$ in neighbourhood $i$, and $H_{c}$ is the total population of non-Muslims in city $c^{15}$.

I construct this measure using religion indicators in the Sixth Economic Census conducted by the Ministry of Statistics and Program Implementation, Government of India (MoSPI,

\footnotetext{
${ }^{15}$ See Appendix $\mathrm{C}$ for a detailed discussion.
} 


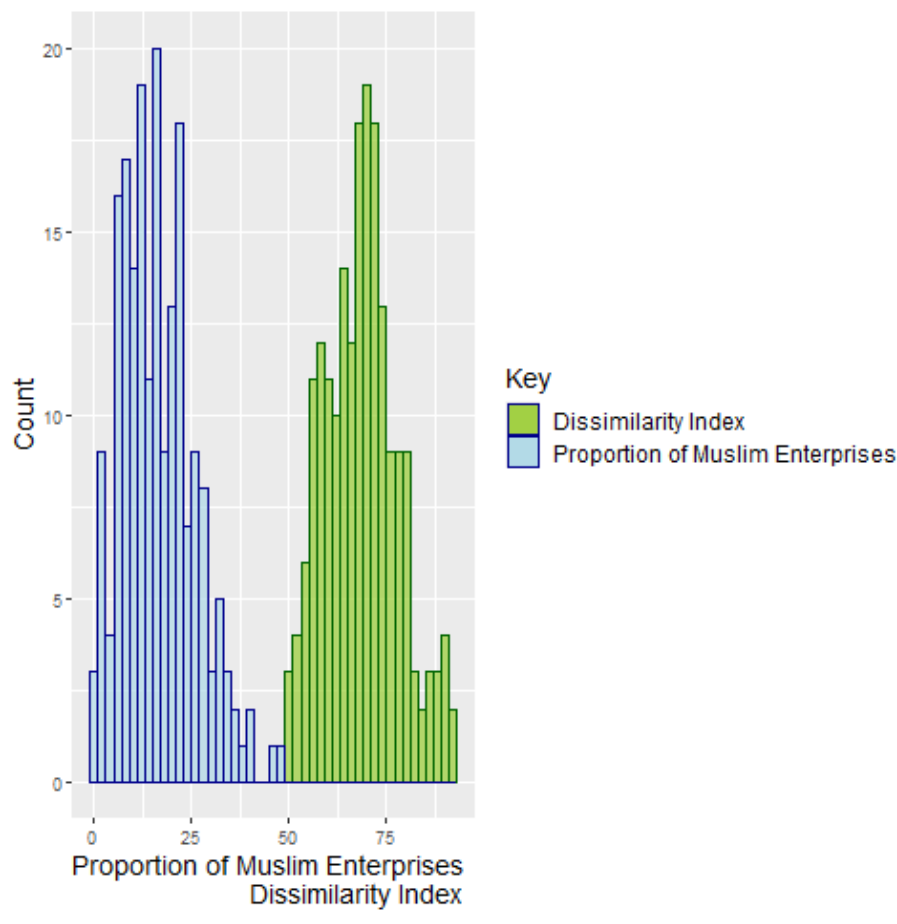

Figure 5: Distribution of dissimilarity indices, and Proportion of Muslim Enterprises across Indian cities

2013) for about 25 million residential and residential-cum-commercial enterprises all over India. This data is available at the level of enumeration block (henceforth, EB), where every EB contains about 80 to 200 households. Figure 5 shows the distribution of the segregation measure and proportion of Muslim owned enterprises across Indian cities computed using this data.

\subsection{Town Level Attributes}

I link the Dissimilarity Indices (from (9)), constructed using Economic Census, to Town Directories of the Population Census (1990, 2000 and 2010), compiled by the Ministry of Statistics and Program Implementation, Government of India (MoSPI, 2011). The linking of the Economic Census and Population Census was done using Socio-Economic High Resolution Rural-Urban Geographic (SHRUG) Platform for India (Asher et al., 2019). 
I use the Town Directories from the Population Census to get city level attributes like urban population, number of primary and secondary schools (both public and private), and number of colleges and universities, over time.

Before moving on to the empirical strategy in Section 2, I summarize the variables of interest in Table 2.

\begin{tabular}{ccccc}
\hline Variable Name & Notation & Across City & Across Households & Time/ Cohort \\
\hline Distance from Yatra Route & $z_{c}$ & Yes & No & No \\
Segregation Measure & $\theta_{c}$ & Yes & No & No \\
Violence & $\rho_{c}$ & Yes & No & Yes \\
Whether attained Education Level $e$ & $\sigma_{i h c t}^{e}$ & Yes & Yes & Yes \\
Whether Muslim & $d_{i h c}$ & Yes & Yes & No \\
City Controls & $X_{c t}$ & Yes & No & Yes \\
Household Controls & $X_{h c t}$ & Yes & Yes & Yes \\
\hline
\end{tabular}

Table 2: Variation in variables on interest

\section{Empirical Strategy}

I measure the effect of communal violence on education attainment for Muslims in India. However, Mitra and Ray (2014) demonstrate that rioting is correlated with relative incomes (measured by consumption expenditures) levels of Hindus and Muslims. This, in turn, is correlated with schooling choices, thus biasing the OLS estimates due to omitted variables. Therefore, I exploit quasi-random exposure of cities to communal violence. I obtain this variation in riots by tracing the path of the Ram Rath Yatra (1990). I check that distance from Yatra is in fact uncorrelated with relative Muslim incomes over time ${ }^{16}$.

I propose my preferred instrument for communal violence: the distance of a town from the Yatra route, as it actualized in reality. I restrict the sample to the states that were exposed to the Yatra campaign. I have already demonstrated that a disproportionate share of riots in 1990-93 occurred on or very close to the Yatra route in Figure 3.

\footnotetext{
${ }^{16}$ This helps to address valid issues raised by Mitra and Ray (2014). See Figure 8.
} 
First, I employ random effects regressions to establish the relationships between education outcomes and distance from Yatra. Second, I check the robustness of my reduced form results by administering placebo treatments. This is done by exploiting the difference between the planned and actual campaign route. Third, I demonstrate balance in control variables with respect to distance from Yatra and specify a matching design with continuous treatments, to correct for selection on observables. Fourth, I describe my strategy to test residential segregation as a channel through which communal violence impacts education outcomes. Finally, I write down the additional assumptions required to estimate the impact of segregation on education outcomes of Muslims, using distance from Yatra as an instrument.

\subsection{Reduced Form Specification}

I measure the relationship between Muslim education attainment and distance of a city from the Yatra route. On account of the timing of the event (September-October, 1990), I expect different cohorts across religious lines to respond to the event differently. In particular, cohorts born after 1985 are hypothesized to begin schooling after facing displacement on account of Yatra riots. Cohorts born between 1981 and 1985 are assumed to already be in school by 1990. Cohorts born before 1971 would have completed schooling by this time. Then, the probability for Muslims of cohort $t$ to have attained education level $e$ is

$$
\begin{array}{r}
\sigma_{\text {ihct }}^{e}=\alpha+d_{i h c}+\gamma \log \left(z_{c}\right)+\sum_{t} \delta_{t} I(\text { born }=t)+ \\
\sum_{t} \beta_{t} \log \left(z_{c}\right) \cdot I(\text { born }=t) \cdot d_{i h c}+ \\
\phi X_{h c t}+\xi_{c t}+\varepsilon_{i h c t}
\end{array}
$$

where, $\sigma_{i h c t}^{e} \in\{0,1\}$ indicates whether individual $i$ in household $h$, city $c$ and cohort $t$ attained education level $e \in\{$ Primary, Secondary or College $\}, d_{i h c}$ is dummy coded indicating whether household is Muslim, $t \in\{1961-65,1966-70,1971-75,1976-80,1981-$ $85,1986-90\}$ depicts the cohort an individual belongs to and $I(\cdot)$ is an indicator function, $z_{c}$ denotes distance of city $c$ from Yatra route in kilometres, $X_{h c}$ and $\xi_{c}$ are household level controls and random effects for city $c$ respectively, $\varepsilon_{i h c t}$ is the random error term. The pairs 
of cross-products from the triple difference term were dropped from (2) for brevity. $\beta_{t}$ 's are correctly estimated under the following assumptions:

$$
\begin{gathered}
\mathrm{E}\left[\xi_{c t} \mid \log \left(z_{c}\right)\right]=0 \\
\mathrm{E}\left[\xi_{c t} \mid I(b o r n=t)\right]=0 \\
\mathrm{E}\left[\xi_{c t} \mid d_{i h c}\right]=0
\end{gathered}
$$

These conditions imply that there are no time-varying unobservable characteristics of a city that vary with the distance from the campaign route in a discernible pattern (A1), or that impact various generation of cohorts (A2) and Muslims (A3) differently. In order to check the validity of these assumptions (and in the absence of unobservable city characteristics), I check how various time-varying observable characteristics of a city relate with $z_{c}$.

(A2) is the most tenable assumption, as timing of birth is unrelated to city characteristics. However, Figure 6 demonstrates that cities closer to the route are more populous (and larger), and in this way (A1) may be violated. 


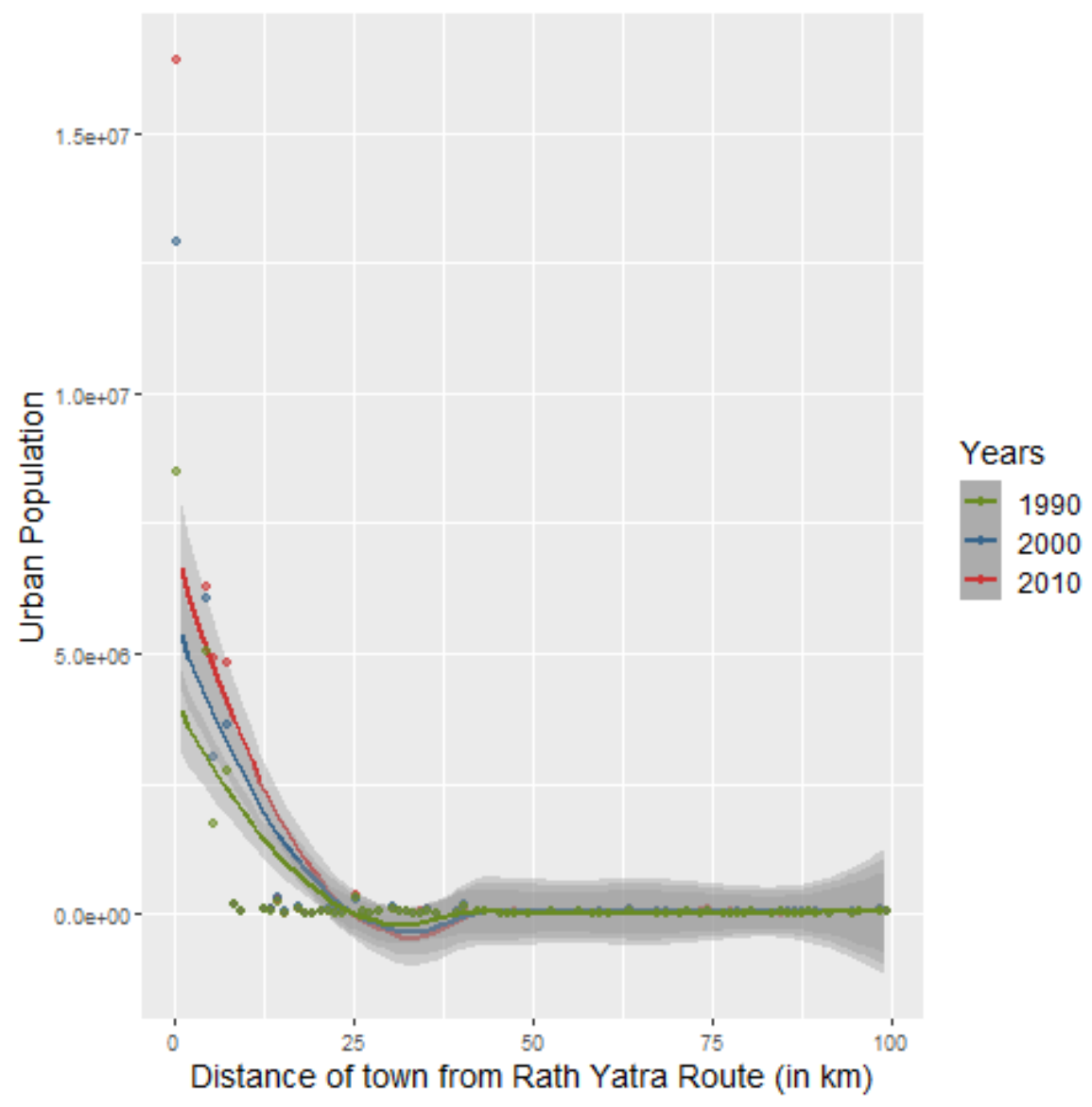

Figure 6: Total urban population as a function of Distance from Yatra.

I further divide the sample of cities within 250 kilometres of the Yatra route into five subsamples, in intervals of 50 kilometres each. In Table 3, I find that cities closest to the route (0 to 50 kilometres) are more populous in all three Census years under consideration. The remaining four groups, however, are indistinguishable in terms of urban population.

\begin{tabular}{cccccc}
\hline \multirow{2}{*}{$\begin{array}{c}\text { Distance from Yatra (in km) } \\
\text { Urban Population }\end{array}$} & $\begin{array}{c}0 \text { to } 50 \\
(\mathrm{~N}=63)\end{array}$ & $\begin{array}{c}50 \text { to } 100 \\
(\mathrm{~N}=52)\end{array}$ & $\begin{array}{c}100 \text { to } 150 \\
(\mathrm{~N}=30)\end{array}$ & $\begin{array}{c}150 \text { to } 200 \\
(\mathrm{~N}=21)\end{array}$ & $\begin{array}{c}200 \text { to } 250 \\
(\mathrm{~N}=16)\end{array}$ \\
\cline { 2 - 6 } & Mean (SD) & Mean (SD) & Mean (SD) & Mean (SD) & Mean (SD) \\
\hline 2010 & $860,772(2,891,720)$ & $42,831(21,389)$ & $51,719(23,873)$ & $46,532(22,279)$ & $61,608(40,284)$ \\
2000 & $711,609(2,392,860)$ & $44,498(18,465)$ & $52,610(23,772)$ & $47,561(21,078)$ & $69,836(45,792)$ \\
1990 & $528,602(1,772,673)$ & $34,963(12,855)$ & $41,373(18,612)$ & $39,743(22,183)$ & $51,743(35,830)$ \\
\hline
\end{tabular}

Table 3: Balance of Urban Population across groups (by distance from Yatra). 
Table 4, on the other hand, demonstrates that the most populous cities (which are closer to the Yatra route) are not different from all other cities in terms of supply of school and college infrastructure, over the years. The difference in city size (by continuous treatment) can potentially bias my estimates, and I describe strategies to address this problem in Section 2.3 .

\begin{tabular}{cccccc}
\hline \multirow{2}{*}{ Distance from Yatra (in km) } & $\begin{array}{c}0 \text { to } 50 \\
(\mathrm{~N}=63)\end{array}$ & $\begin{array}{c}50 \text { to } 100 \\
(\mathrm{~N}=52)\end{array}$ & $\begin{array}{c}100 \text { to } 150 \\
(\mathrm{~N}=30)\end{array}$ & $\begin{array}{c}150 \text { to } 200 \\
(\mathrm{~N}=21)\end{array}$ & $\begin{array}{c}200-250 \\
(\mathrm{~N}=16)\end{array}$ \\
\cline { 2 - 6 } Schools & Mean (SD) & Mean (SD) & Mean (SD) & Mean (SD) & Mean (SD) \\
\hline Primary & & & & & \\
2010 & $4.64(2.27)$ & $5.81(2.38)$ & $5.43(2.02)$ & $5.73(2.48)$ & $6.01(1.95)$ \\
2000 & $4.14(2.33)$ & $3.94(1.22)$ & $3.80(1.31)$ & $4.18(1.66)$ & $5.09(5.05)$ \\
1990 & $3.47(1.28)$ & $3.70(0.98)$ & $3.38(1.07)$ & $4.16(1.83)$ & $3.77(1.80)$ \\
\hline Secondary & & & & & \\
2010 & $1.62(0.88)$ & $2.19(1.18)$ & $2.05(1.00)$ & $1.84(0.73)$ & $1.96(0.71)$ \\
2000 & $1.35(0.71)$ & $1.34(0.60)$ & $1.27(0.81)$ & $1.58(0.68)$ & $1.30(0.61)$ \\
1990 & $1.15(0.51)$ & $1.17(0.45)$ & $1.07(0.42)$ & $1.20(0.37)$ & $0.95(0.46)$ \\
\hline College & & & & & \\
2010 & $0.79(0.46)$ & $1.06(0.62)$ & $1.04(0.71)$ & $0.67(0.41)$ & $0.97(0.71)$ \\
2000 & $0.41(0.40)$ & $0.45(0.20)$ & $0.41(0.29)$ & $0.37(0.18)$ & $0.39(0.15)$ \\
1990 & $0.65(0.41)$ & $0.82(0.48)$ & $0.83(1.04)$ & $0.80(0.42)$ & $0.67(0.42)$ \\
\hline
\end{tabular}

Table 4: Balance of school and college infrastructure, per 10,000 urban residents (by distance from Yatra).

Next, I discuss the credibility of assumption A3. That is, I check if there are time-varying city characteristics that vary with proportion of urban Muslim population. In Figure 7, I plot the percentage share of Muslims sampled in the NSS surveys over the years, as well as percentage of Muslim enterprises from the Economic Census in 2013. 


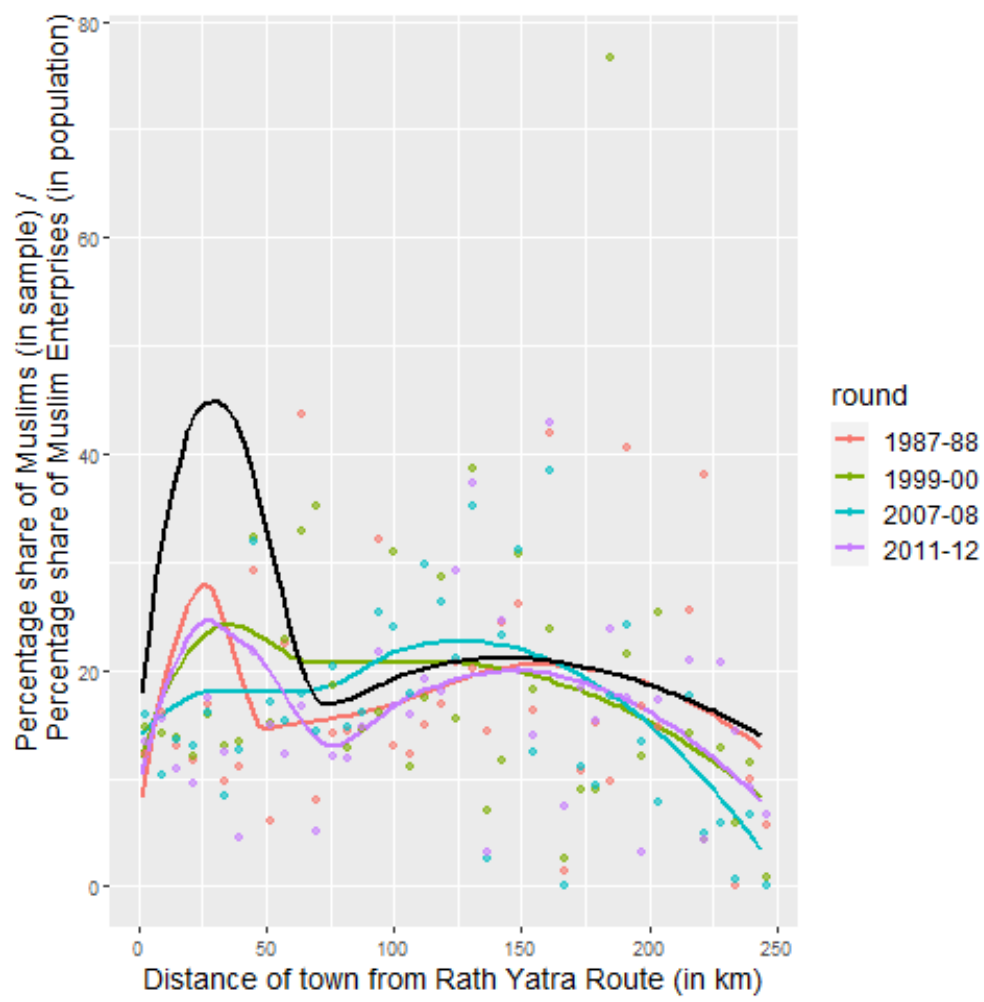

Figure 7: Proportion of Muslim households in NSSO samples over various round, and Muslim enterprises in Economic Census (black solid line) in 2013, by distance from Yatra route.

From Figure 7, I cannot conclude that Muslim population is distributed differently by distance, pre- and post-1990. It is, however, clear that the odds of finding Muslim-owned enterprises are higher within the first 50 kilometres of the Yatra route in the year 2013. Another important household characteristic is income, which I proxy with Monthly Per Capita Expenditures (hencefoth, MPCE). Figure 8 shows that there is no relationship between the instrument and MPCE (normalized to 1983 Rupees), over the years. 


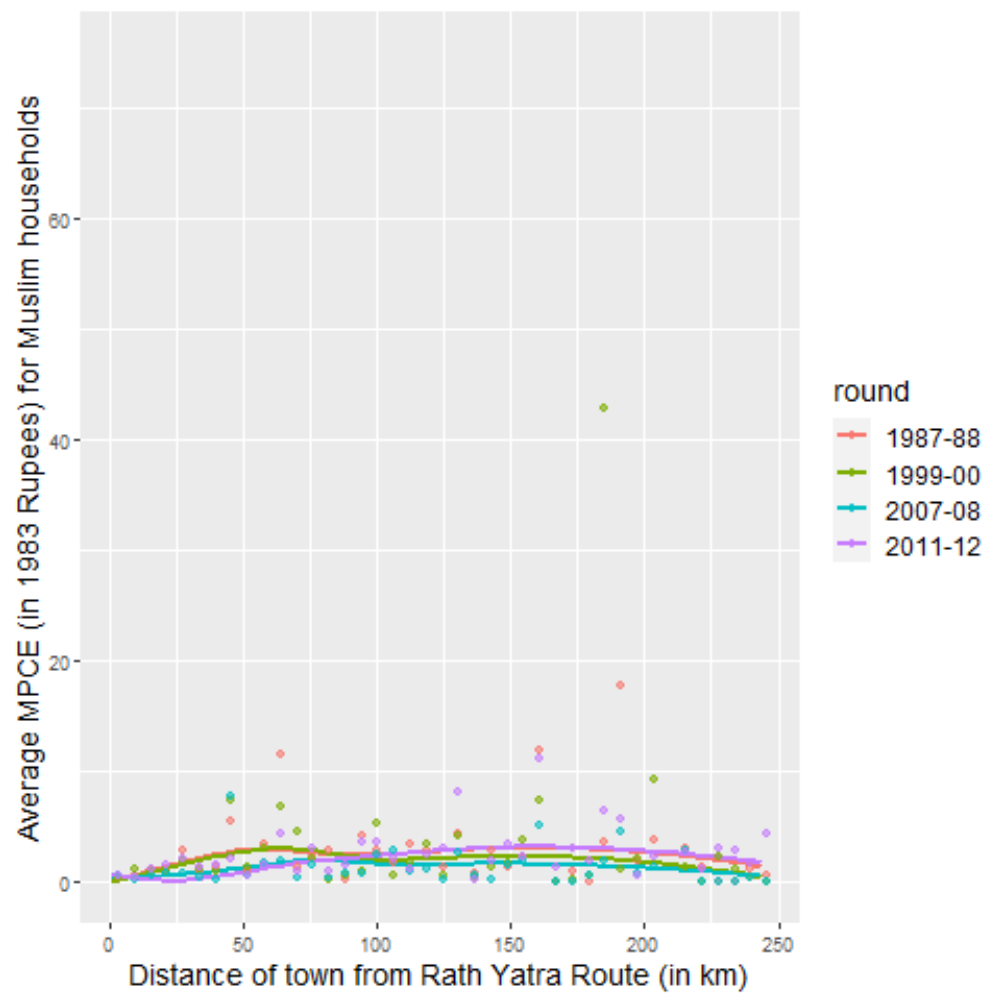

Figure 8: Muslim Monthly Per Capita Consumption (in 1983 Rupees) relative to non-Muslim MPCE, as a function of distance from Yatra route.

This assuages the threat to identification raised by Mitra and Ray (2014), who found that higher Muslim MPCEs relative to Hindu MPCEs, were correlated with the higher probability of communal violence. This is because, in my sample, the probability of a riot is higher closer to the campaign route, but average Muslim MPCEs (relative to non-Muslim MPCEs) seem to be uniformly distributed in the sample, both pre- and post- Yatra.

\subsection{Placebo Yatra}

On October 23, 1990, the state government of Bihar issued orders to arrest prominent BJP leader, LK Advani, who was spearheading the Ram Janmabhoomi campaign (Yadav, 2017). This brought the Ram Rath Yatra to an unexpected halt, a week before it was supposed to reach it's final destination in Ayodhya, UP. I exploit exogeneity in the timing (and therefore, 
the location) of this arrest, to construct a placebo treatment. This is done by charting out the planned route which the campaign was unable to tread due to this arrest. I find no correlation between the placebo route and the number of riots occurring in a city until the ultimate demolition of Babri Masjid in December, 1992.

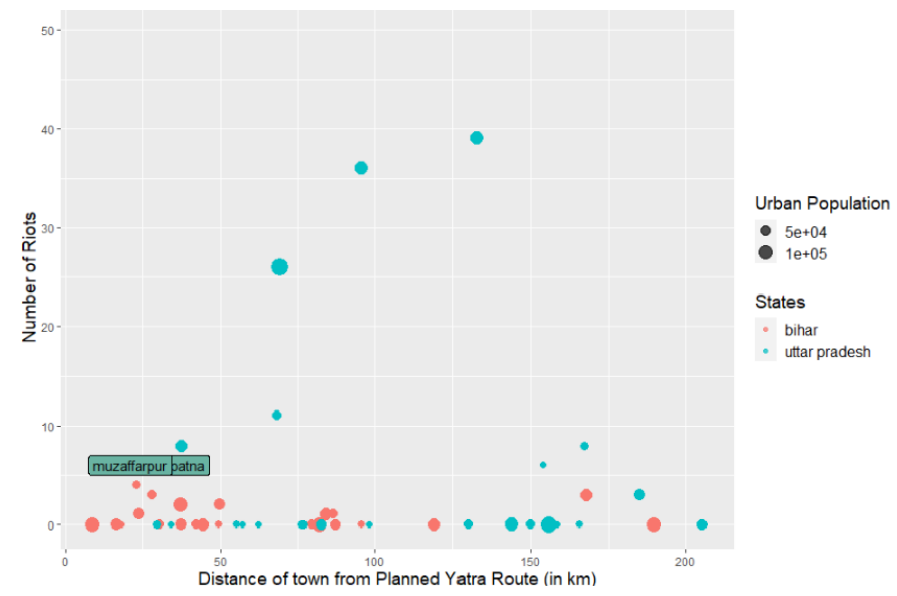

Figure 9: Number of riots (1990-93) by distance from placebo Yatra route.

Figure 9 presents a contrasting picture with respect to Figure 3, where I saw a strong and negative relationship between rioting and the continuous treatment. It is worth mentioning that rioting occurred in the labelled districts of Patna and Muzaffarpur, that are close to the placebo route. However, note that both these districts are right next to Samastipur district, where LK Advani was in fact arrested. It is therefore, more likely, that rioting here was on account of the treatment, and not the placebo.

Then, I estimate the reduced-form equation (2) again, this time with respect to distance from the placebo Yatra

$$
\begin{array}{r}
\sigma_{i h c t}^{e}=\alpha+d_{i h c}+\gamma \log \left(z_{c}^{P}\right)+\sum_{t} \delta_{t} I(\text { born }=t)+ \\
\sum_{t} \beta_{t} \log \left(z_{c}^{P}\right) \cdot I(\text { born }=t) \cdot d_{i h c}+ \\
\phi X_{h c t}+\xi_{c t}+\varepsilon_{i h c t}
\end{array}
$$

where, $z_{c}^{P}$ denotes the placebo Yatra route, and the remaining notation from above remains 
the same.

\subsection{Propensity Score Matching with Continuous Treatment}

Using various observable characteristics of the sample cities, I demonstrated in Section 2.1 that cities closer to the Yatra route are more populous (and bigger), than cities away from it. I also showed that it was more likely to find a Muslim-owned enterprise in the first 50 kilometres of the Yatra route, in the post-treatment period. Therefore, I estimate the model in (2) by matching propensity scores calibrated for continuous treatment, following Hirano and Imbens (2004).

To remain consistent with standard notation in the literature, I denote potential outcomes as $Y_{i h t c}\left(z_{c}\right)$ (education outcomes, previously denoted as $\sigma_{i h t c}^{e}$ ), for $z \in Z$, where $Z$ is continuous treatment (distance from Yatra route) in interval $\left[z_{0}, z_{1}\right]$. Dropping subscripts, the main assumption is described as

$$
Y(z) \perp Z \mid X \text { for all } z \in Z
$$

where, $X$ denotes various city level controls. Then under (A4), I define the generalized propensity score (henceforth, GPS), $R=r(Z, X)$ as the conditional density of the treatment conditional on covariates, i.e.

$$
r(z, x)=f_{Z \mid X}(z \mid x)
$$

Then, $X \perp 1\{Z=z\} \mid r(z, X)$, which implies that assignment to treatment is not confounded, given the GPS. That is,

$$
f_{Z}(z \mid r(z, X), Y(z))=f_{Z}(z \mid r(z, X))
$$

Following Robins et al. (2000), I calculate stabilized inverse probability weights (henceforth, IPW) as:

$$
\iota^{s}=\frac{f_{Z}^{(z)}}{f_{Z \mid X}^{(z \mid x)}}
$$


Assuming $Z_{c} \mid X_{c} \sim N\left(\beta_{0}+\beta_{1}^{\prime} X_{c}, \sigma^{2}\right)$, with $X_{c}$ being city level attributes like urban population in 1990, I estimate stabilized IPWs ${ }^{17}$. Furthermore, I plot the density of $\iota^{s}$ in Figure 10 , and find that it is centred around 1.

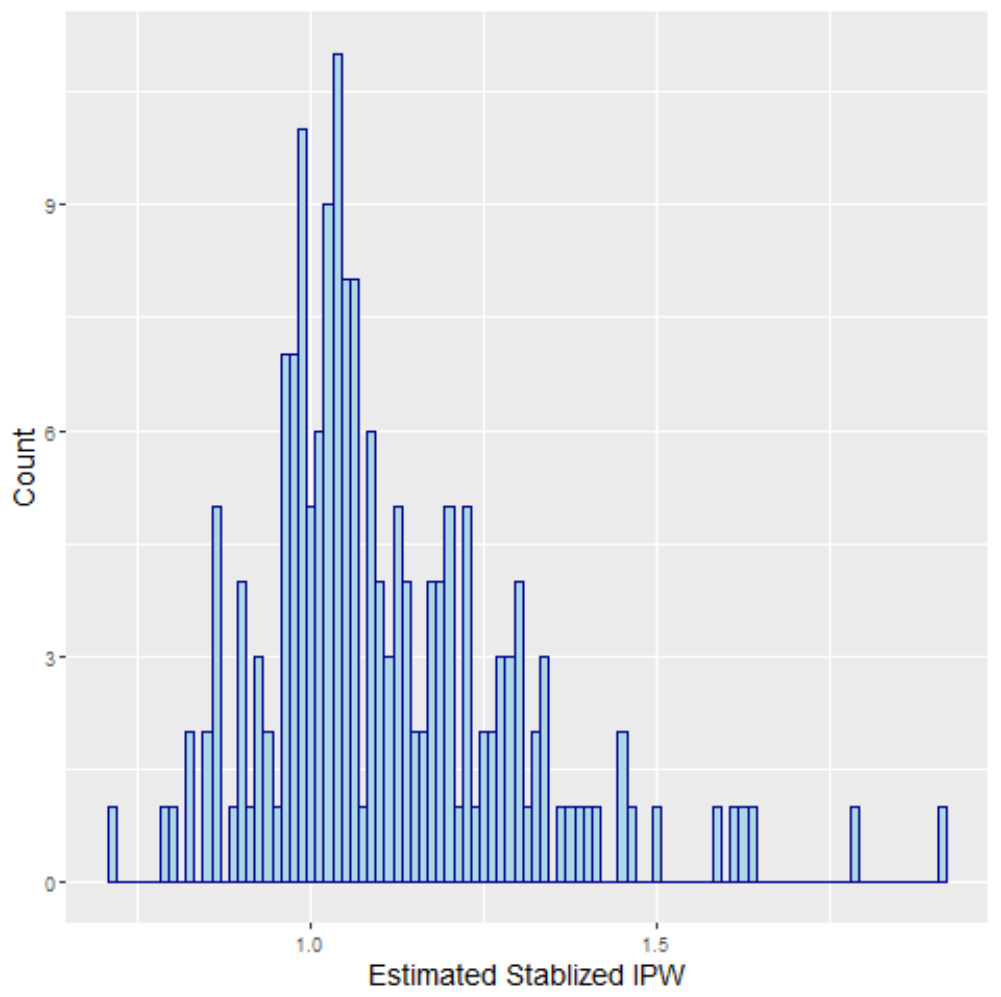

Figure 10: Sample distribution of estimated Stabilized Inverse Probability Weights (IPW).

I check if stabilized IPWs are systematically related with the treatment. In Figure 11, I do not find that the weights co-vary with the continuous treatment in an identifiable way. This grants greater credibility to the research design.

\footnotetext{
${ }^{17}$ I fit the distribution of continuous treatment with a function that is piece-wise linear in urban population of 1990, by estimating a spline regression.
} 


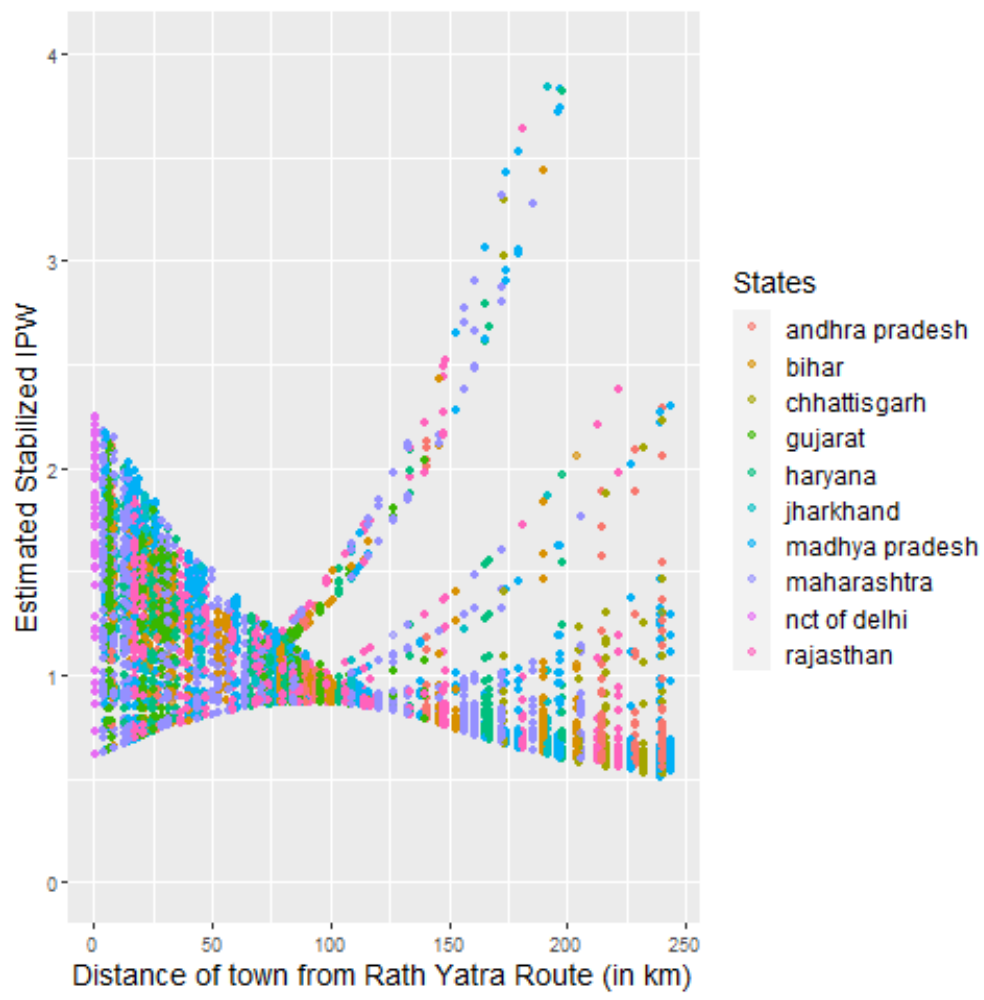

Figure 11: Correlation between estimated Stabilized Inverse Probability Weights (IPWs) and distance from Yatra route

\subsection{Channels: Neighbourhood Effects}

In light of the reduced form results obtained from the specifications above, I explore if segregation of communities along religious lines drives the effects of violence on Muslim education outcomes. I estimate the static relationship between segregation $\left(\theta_{c}\right)$ and distance from the route $\left(z_{c}\right)$, while controlling for city level observables $\left(X_{c}\right)$ as:

$$
\theta_{c}=\alpha+\tau \log \left(z_{c}\right)+\psi X_{c}+\mu_{c}
$$

I also estimate the relationship between segregation and the placebo treatment, that is the distance from the planned Yatra route. This lends greater credibility to the stipulated channel. Additionally, I verify that there is no treatment effect on untreated groups 
like Scheduled Castes, as I test the hypothesis that distance of a city from Yatra route is uncorrelated with dissimilarity index constructed according to caste and not religion.

I hypothesize that segregation of Muslim and Hindu neighbourhoods in Indian cities drives better early education outcomes for Muslims in locations that were more susceptible to communal conflict. The ideal experiment to uncover causal effects of neighbourhood characteristics on individual education outcomes, would assign the opportunity to live in segregated or integrated neighbourhoods randomly. However, in addition to manipulating the composition of neighbourhoods, communal violence along the campaign trail may change the political environment in a way that changes the likelihood of going to school, for different groups differently.

Following Abdulkadiroğlu et al. (2014), I postulate a vector $m_{i c}$ assumed to contain education inputs like composition of neighbourhood, parental income, measures of school quality, and political environment or discriminatory attitudes towards Muslims. Then, the education production function, dropping cohort and household subscripts, is given by

$$
\sigma_{i c}^{e}=\pi^{\prime} m_{i c}+\eta_{i c}
$$

where, $\eta_{i c}$ is the randomness in potential outcomes revealed under alternative assignments of the input bundle $m_{i c}$ for individual $i$, residing in city $c$. Furthermore, I can partition $m_{i c}$ into observed segregation levels for a Muslim individual $i$ in city $c, \theta_{i c}$, as well as unobserved inputs $w_{i c}$. Then, the structural education production function can be written as:

$$
\sigma_{i c}^{e}=\delta^{\prime} \theta_{i c}+\lambda^{\prime} w_{i c}+\eta_{i c}
$$

where, $\theta_{i c}$ is dissimilarity index $\left(\theta_{c}\right)$ interacted with a dummy variable that is equal to 1 for Muslims $\left(d_{i c}\right)$. Then, the instrumental variable, $z_{i c}$, is given by distance of a city from Yatra route $\left(z_{c}\right)$ interacted with the Muslim dummy. Here, I assume that the instrument is independent of potential outcomes, i.e. independent of $\eta_{i c}$. However, the instrument does not meet the exclusion restriction as not only does Yatra change the composition of neighbourhoods, it also changes unobserved inputs in (7). That is,

$$
\begin{aligned}
& \theta_{i c}=\omega_{1}^{\prime} z_{i c}+\nu_{1 c} \\
& w_{i c}=\omega_{2}^{\prime} z_{i c}+\nu_{2 c}
\end{aligned}
$$


With this structure, the 2SLS estimate using $z_{i c}$ as an instrument for $\theta_{i c}$, omitting $w_{i c}$ identifies $\delta+u^{\prime} \lambda$, where $u$ is the population 2SLS coefficient vector from a regression of $w_{i c}$ on $\theta_{i c}$, using $z_{i c}$ as instrument ${ }^{18}$. Then, suppose if $u$ and $\lambda$ are positive, 2SLS estimates of neighbourhood effects, omitting $w_{i c}$, tend to be too big.

Building on the existing literature, I will provide evidence that $\lambda$ is in fact negative, while maintaining the assumption that $u>0$. That is to say, while the unobservables co-vary with the segregation measure, $w_{i c}$ impacts education outcomes negatively. Therefore, under weaker assumptions on the bias induced by unobserved inputs in the education production function, I will show in Section 3, that the direction of neighbourhood effects on Muslim education attainment is positive.

I empirically interrogate the effect of neighbourhood as a channel for improved education outcomes for Muslim children who started school after the violent events in 1990. I estimate the following structural relationship

$$
\begin{array}{r}
\sigma_{i h c t}^{e}=\alpha+d_{i h c}+\gamma \hat{\theta}_{c}+\sum_{t} \delta_{t} I(\text { born }=t)+ \\
\sum_{t} \beta_{t} \hat{\theta}_{c} \cdot I(\text { born }=t) \cdot d_{i h c}+ \\
\phi X_{h c t}+\xi_{c t}+\varepsilon_{i h c t}
\end{array}
$$

where $\hat{\theta}_{c}$ is estimated in (6). First, I assume that the only channel through which distance from Yatra influences education outcomes for Muslims, is through residential segregation. I then relax this assumption in line with (7), and show that the neighbourhood effects are positive. Next, I turn to the obtained results.

\section{Results}

In this Section, I implement the empirical strategy delineated in Section 2.

\footnotetext{
${ }^{18}$ see Proposition 1 in Abdulkadiroğlu et al. (2014).
} 


\subsection{Reduced Form Specification}

In order to correctly estimate (2), I want to ensure that the education levels of cohorts (both Muslims and Non-Muslims) attending school prior to 1990, are not affected differently. That is, I expect education levels of Muslims born after 1981 (aged between 0 to 9 in 1990) to be differentially impacted by distance of their city to Yatra route. In Figure 12, I find parallel trends in the probability that Muslims and Non-Muslims attend Primary School with respect to the treatment, for cohorts who had already finished schooling by 1990 .

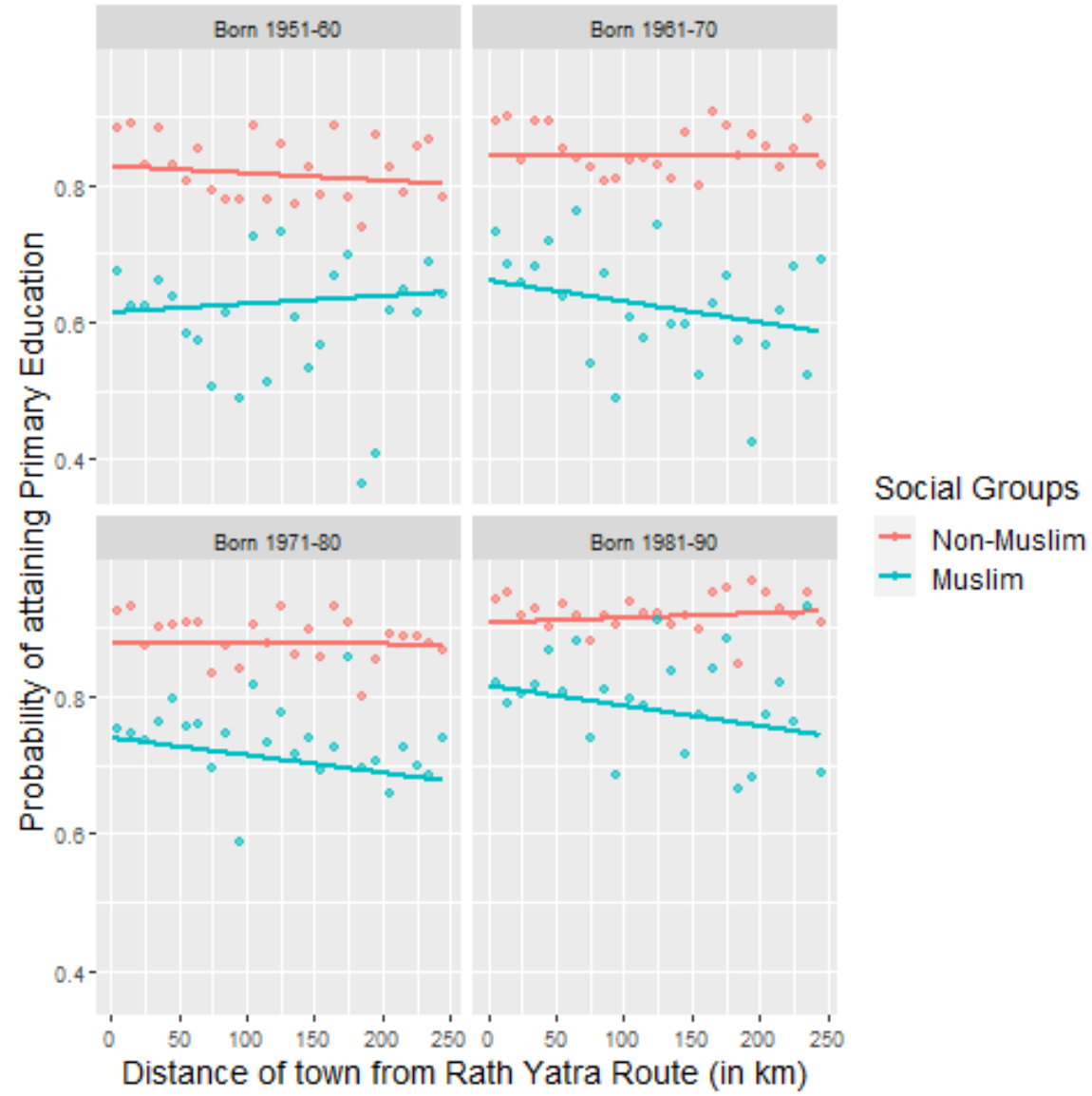

Figure 12: Probability of attaining primary education by religion, cohort, and distance from Yatra

I check if the parallel trends assumption is satisfied for other outcome variables, namely 
probability of attending secondary school and college in Appendix Figures A.1 and A.2. I estimate (2), and present estimates corresponding to completion of primary school in Figure 13.

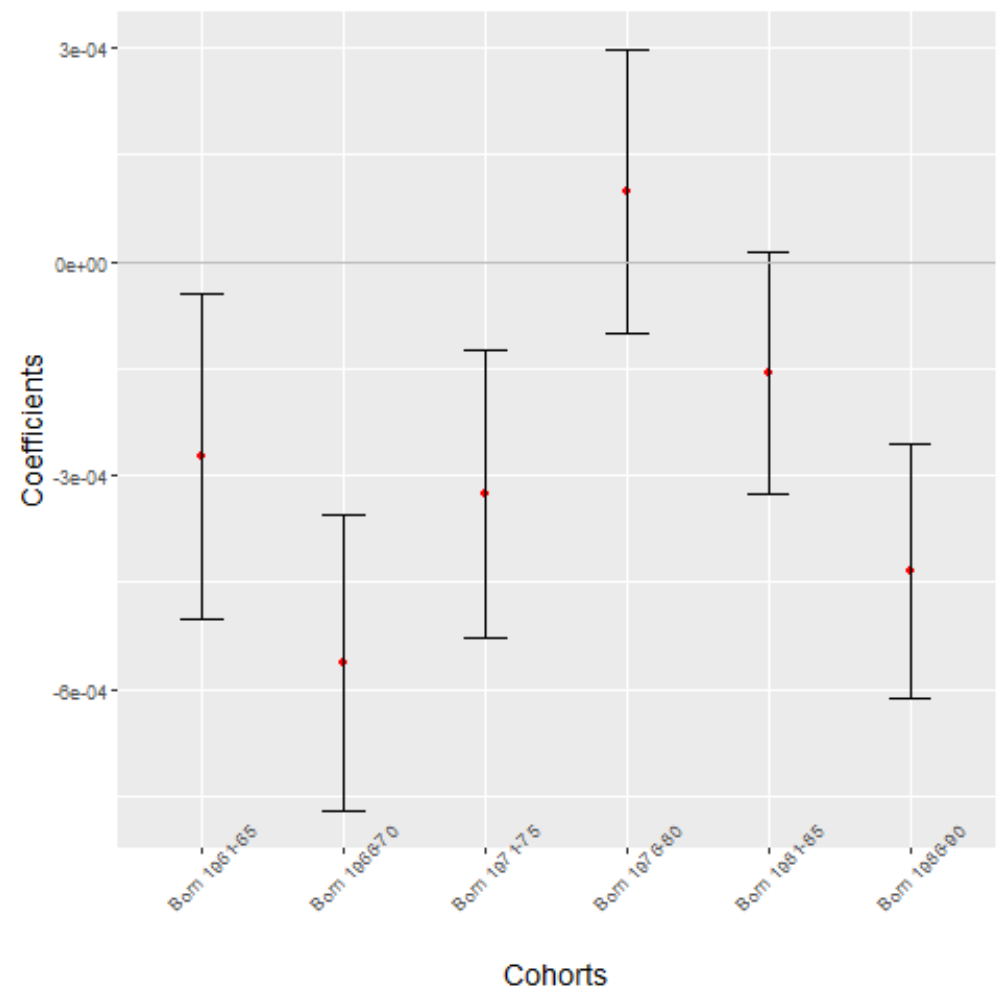

Figure 13: $\hat{\beta}$ 's estimated from (2), for completion of primary school.

For cohorts born after 1986, I find a significantly negative relationship between distance from Yatra and probability of attaining primary education, for Muslims. The corresponding graphs for illiteracy, and attainment of secondary and college education are in Appendix A (Figures A.3, A.4, and A.5).

I find that Muslims born in cities away from the campaign route, after the year 1985, face a disadvantage in terms of early education. That is to say, Muslim children starting school after 1990 performed better in terms of early education attainment in cities that were more susceptible to violence. I do not find any such patterns for secondary and tertiary education attainment. 


\subsection{Placebo Yatra}

I use the arrest of BJP leader, LK Advani, and the subsequent suspension of the campaign to identify parts of the planned route that did not actually see the campaign. As elaborated in Section 2.2, this enables me to construct a placebo test, wherein I check if the same reduced form relationships hold in (3) for the planned, as opposed to the actual Yatra route.

I check if the relationship between the placebo route, and education attainment level of Muslims from various cohorts follows patterns similar to cases when the treatment was actually administered (See Figures 12 and 13). I find that the relationship between primary education attainment and the placebo route is parallel for Muslims and non-Muslims of cohorts born after 1980 (Figure 14), and does not mirror the effects of the treatment. Corresponding graphs for secondary and tertiary education attainment are given by Figures A.6 and A.7. 


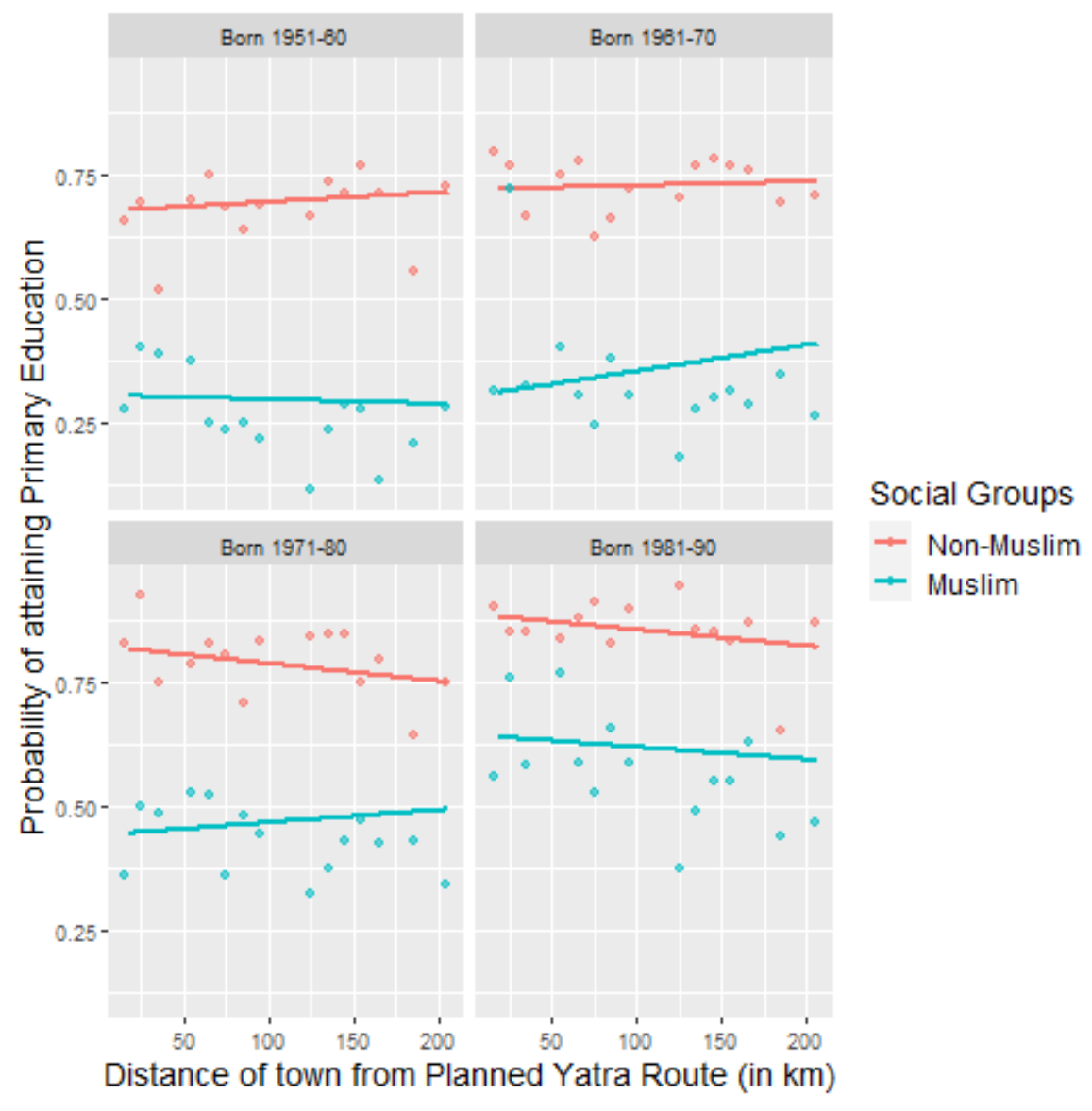

Figure 14: Probability of attaining primary education by religion, cohort, and distance from placebo Yatra.

Finally, I slice the cohorts by 5-year birth intervals and plot the coefficients estimated from (3) in Figure 15. None of the coefficients are significantly different from zero, and I plot the corresponding coefficients for illiteracy, secondary and college education in Figures A.8, A.9, and A.10, respectively. 


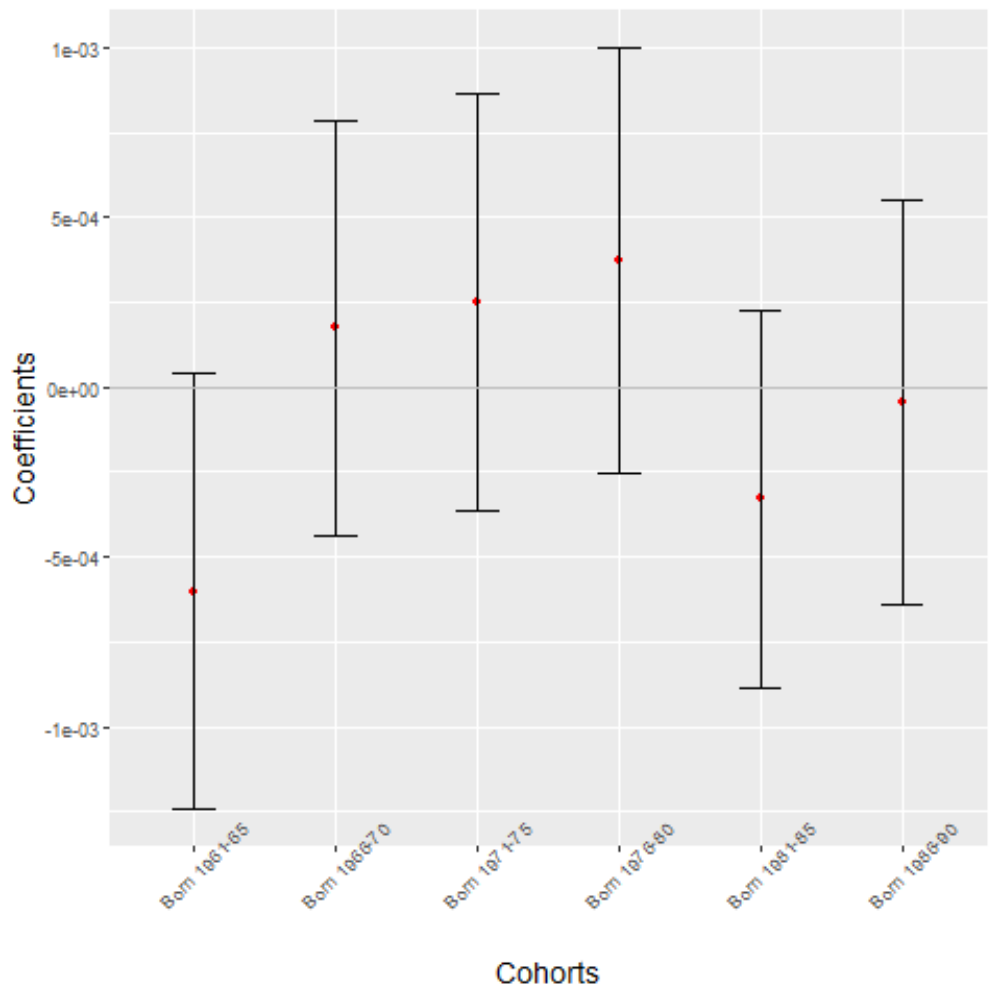

Figure 15: $\hat{\beta}$ 's estimated from (3) with respect to placebo Yatra, for completion of primary school.

Therefore, I have shown that the placebo route has no effects on the outcome variable of interest. This strengthens the reduced form results that were presented in Sections 3.1.

\subsection{Matching Propensity Scores with Continuous Treatment}

I implement the research design laid out in Section 2.3 by reweighting the reduced form equation in (2) using the Stabilized Inverse Probability Weights (IPWs) in (10), computed from the Generalized Propensity Scores (GPS). The sample distribution of estimated IPWs is given by Figure 10, and the absence of correlation between the weights and the treatment is demonstrated by Figure 11. 


\begin{tabular}{|c|c|c|c|c|c|c|}
\hline & (1) & $(2)$ & (3) & (4) & (5) & (6) \\
\hline Born & $1961-65$ & 1966-70 & $1971-75$ & 1976-80 & $1981-85$ & $1986-90$ \\
\hline \multicolumn{7}{|l|}{ Illiteracy Level } \\
\hline \multirow[t]{2}{*}{ Yatra distance $\times$ Muslim } & 0.000308 & 0.000485 & 0.000294 & 0.000109 & 0.000211 & 0.000273 \\
\hline & $(0.0000964)$ & $(0.0000895)$ & $(0.0000896)$ & $(0.0000864)$ & $(0.0000719)$ & $(0.0000747)$ \\
\hline \multicolumn{7}{|l|}{ Primary School } \\
\hline & -0.000162 & -0.000412 & -0.000313 & 0.0000868 & -0.0000231 & -0.000340 \\
\hline & $(0.000108)$ & $(0.000101)$ & $(0.000103)$ & $(0.000102)$ & $(0.0000872)$ & $(0.0000936)$ \\
\hline \multicolumn{7}{|l|}{ Secondary School } \\
\hline & -0.000148 & -0.000517 & 0.000235 & 0.000122 & -0.0000532 & 0.0000915 \\
\hline & $(0.000163)$ & $(0.000159)$ & $(0.000167)$ & $(0.000151)$ & $(0.000144)$ & $(0.000149)$ \\
\hline \multicolumn{7}{|l|}{ College } \\
\hline & 0.000527 & -0.000389 & 0.000282 & 0.0000682 & 0.000206 & 0.000186 \\
\hline & $(0.000236)$ & $(0.000232)$ & $(0.000237)$ & $(0.000220)$ & $(0.000214)$ & $(0.000208)$ \\
\hline
\end{tabular}

Standard errors in parentheses

Table 5: Relationship between distance from Yatra route (in $\mathrm{km}$ ) and education attainment levels for Muslims, weighted by stabilized IPW.

In Table 5, I summarize the relationship between education levels of Muslims from various cohorts with respect to the continuous treatment, weighted by IPWs. I find that all the estimates for early education (illiteracy and primary education attainment levels) retain the same signs as above. Furthermore, primary education attainment for Muslim cohorts born between 1986 and 1990 is significant and negatively related to continuous treatment. This strengthens the result that Muslim children starting school post-Yatra in cities more susceptible to violence attained higher levels of primary education. However, the unweighted estimates seem to have been systematically biased upwards as the absolute value of weighted estimates is now smaller in magnitude. 


\subsection{Channels}

I argue that segregation along religious lines is a channel driving the very surprising and positive effects of communal violence on early education outcomes for Muslims. First, I estimate (6) and analyze the relationship between the continuous treatment and my measure of segregation in Figure 16. In Table B.1, I provide estimates from OLS regressions without city level controls (in column 1), and while controlling for population and proportion of Muslim owned enterprises (column 2). In column 3, I regress the dissimilarity index on log of Yatra distance. In all three cases, I find that the coefficient on the treatment is statistically significant, and negative. Therefore, I can reject the null hypothesis of zero linear relationship between segregation and distance of city from campaign route, as I find a significant and negative relationship between the two.

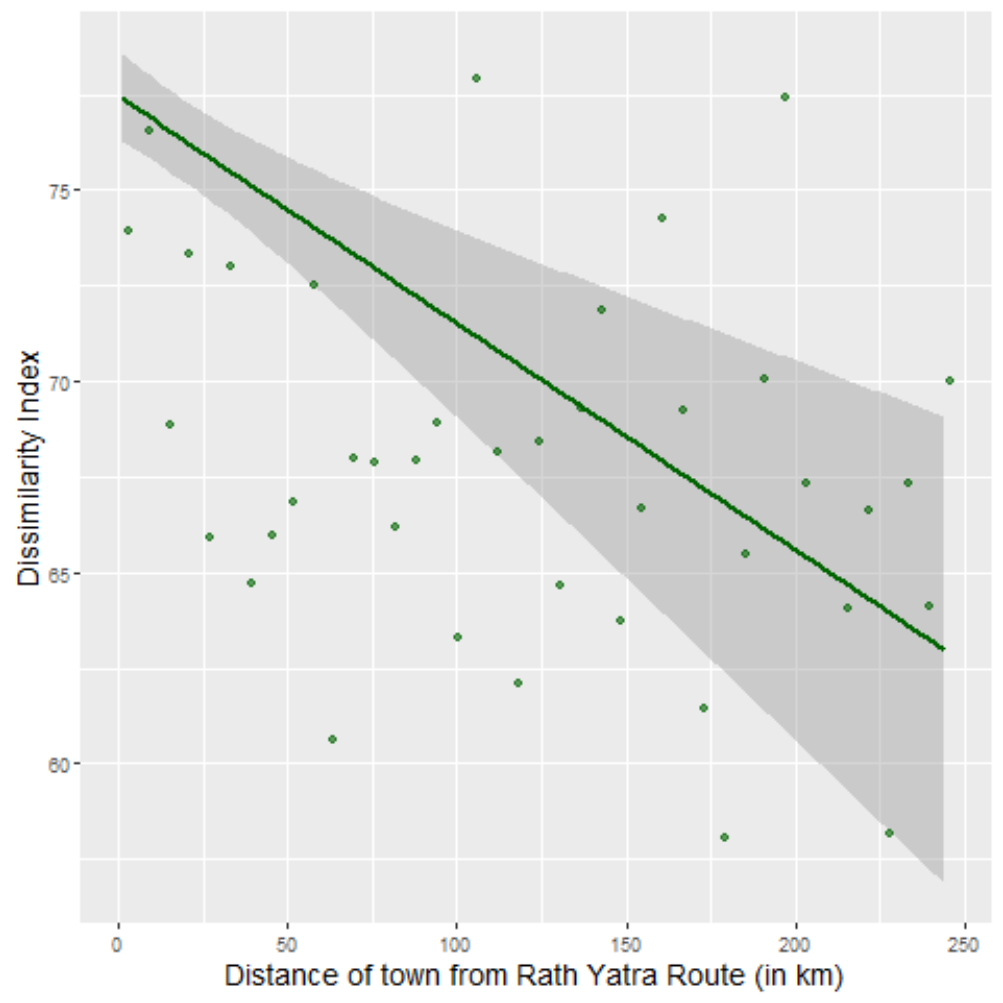

Figure 16: Segregation measure (Dissimilarity Index $\times 100$ ) by Distance from Yatra route.

Second, I demonstrate that the same relationship does not hold with respect to the placebo. 
Figure 17 shows that in Uttar Pradesh, the segregation measure is in fact positively correlated with distance from the placebo route. This is not surprising, as Figure 9 shows that in UP, displacement on account of riots was not more likely to occur closer to the planned route.

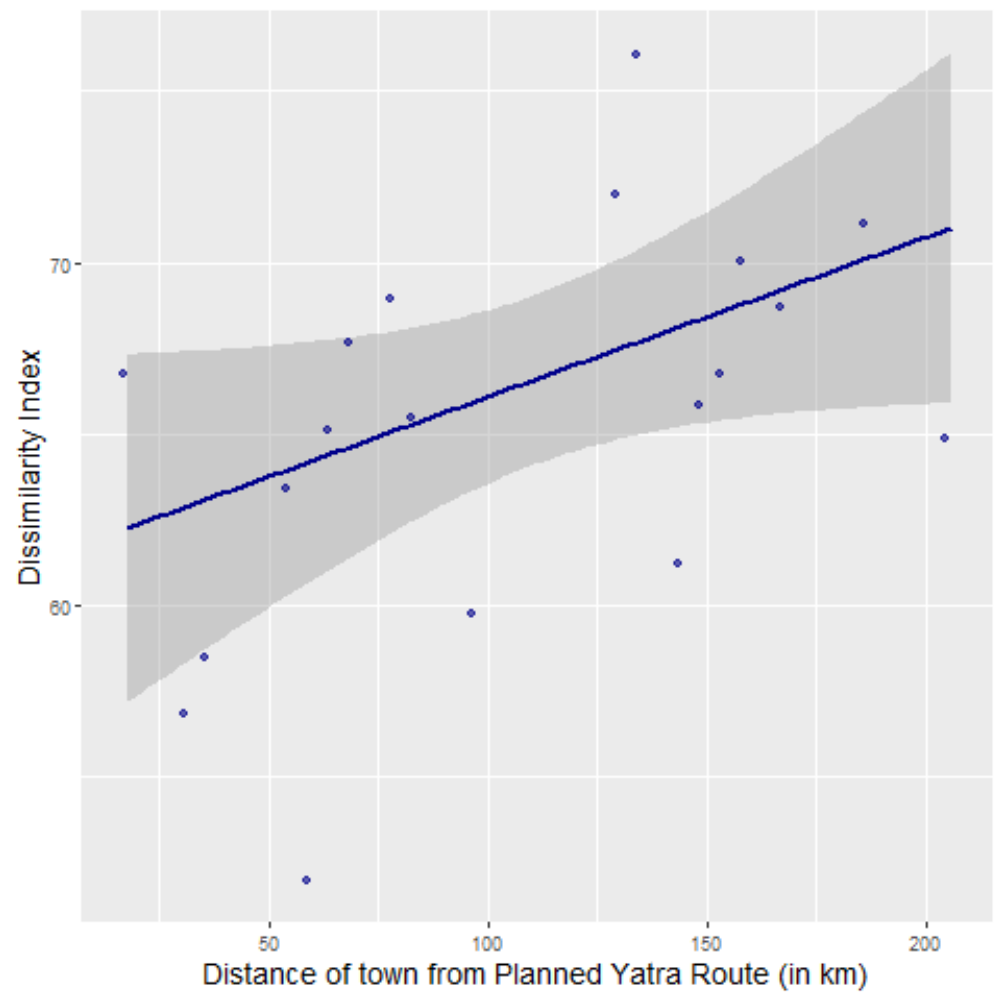

Figure 17: Segregation measure (Dissimilarity Index $\times 100$ ) by Distance from placebo Yatra route.

Finally, I verify that there is no treatment effect on untreated groups. I have used quasirandom variation in communal violence to measure community (or religion) based segregation, as this is a displacement shock that affects Muslims only. In order to verify this, I check if the events of 1990 have any import on residential segregation of Scheduled Castes, who have also been documented to live in segregated enclaves (Bharathi et al., 2018) but are not expected to get displaced due to communal conflicts. I construct caste based dissimilarity indices, using residential and residential-cum-commercial enterprises owned by Scheduled Castes in the Sixth Economic Census (2013). 
In Figure 18, I do not find a statistically significant relationship between caste-based segregation and distance from Yatra. This lends credence to the story that displacement shocks due to Yatra affected Muslims differently.

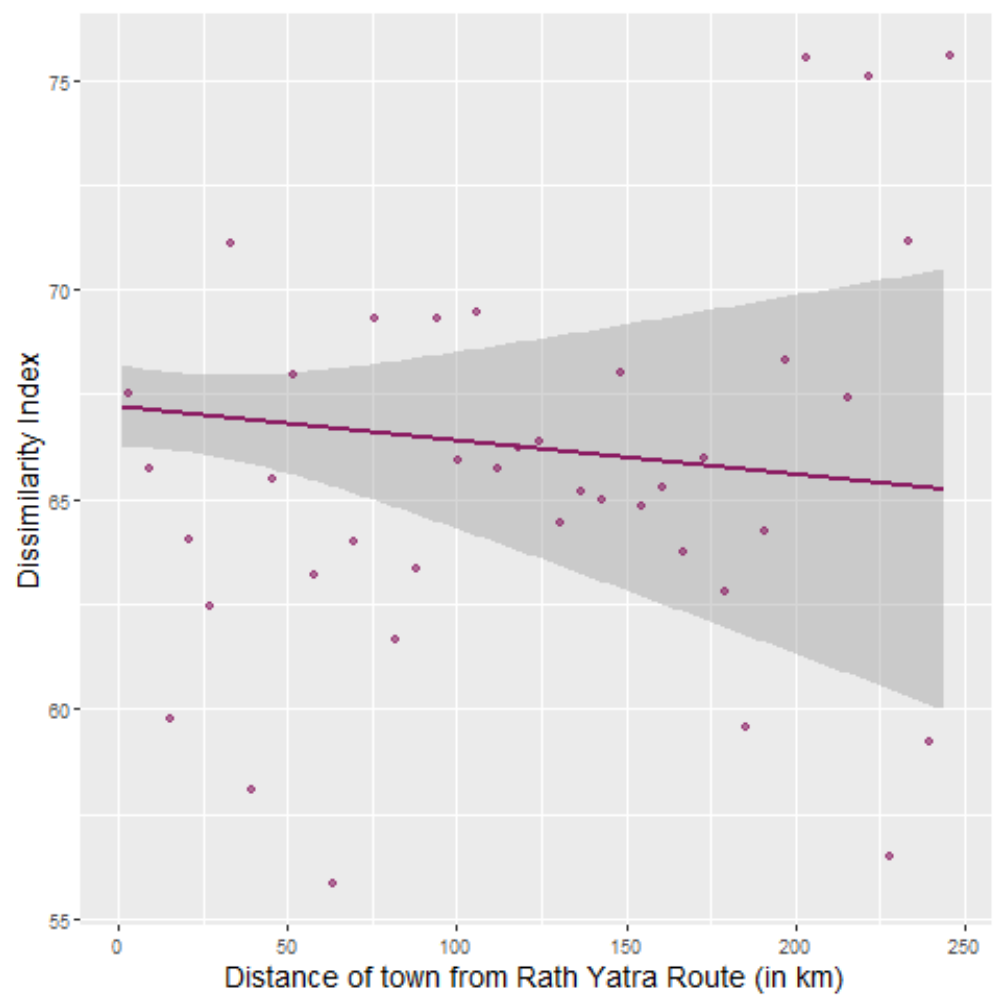

Figure 18: Relationship between caste-based segregation measure (dissimilarity index for scheduled caster $\times 100)$ and distance from Yatra route in kilometres.

Furthermore, I perform robustness checks in Section 4 to show that there is no evidence that education outcomes of the untreated group were differently affected by quasi-random exposure to violence. This is evidenced by the absence of any statistically significant reduced form relationship between distance from Yatra and differences in primary education attainment between Muslims and non-Muslims in Figure 21.

Taking stock of the reduced form estimates in this Section, I now estimate the structural relationship described in $(\star \star)$, where I instrument the segregation measure with distance from Yatra route (according to the first-stage relationship in (6)). 
Table B.1 makes a convincing case for a strong first-stage relationship. In (6), I assume that $\mathrm{E}\left[\mu_{c} \mid z_{c}, X_{c}\right]$. That is to say, conditional on various town characteristics, the only channel through which the treatment impacts education levels is that of segregation. I will later relax this exclusion restriction and show that results remain consistent.

Figure 19 shows that increased segregation leads to increased probability that Muslims born after 1981 attain primary education. Figures A.11, A.12, and A.13 provide the relationship between dissimilarity index and illiteracy levels, completion of secondary and tertiary education for Muslims of various cohorts, respectively.

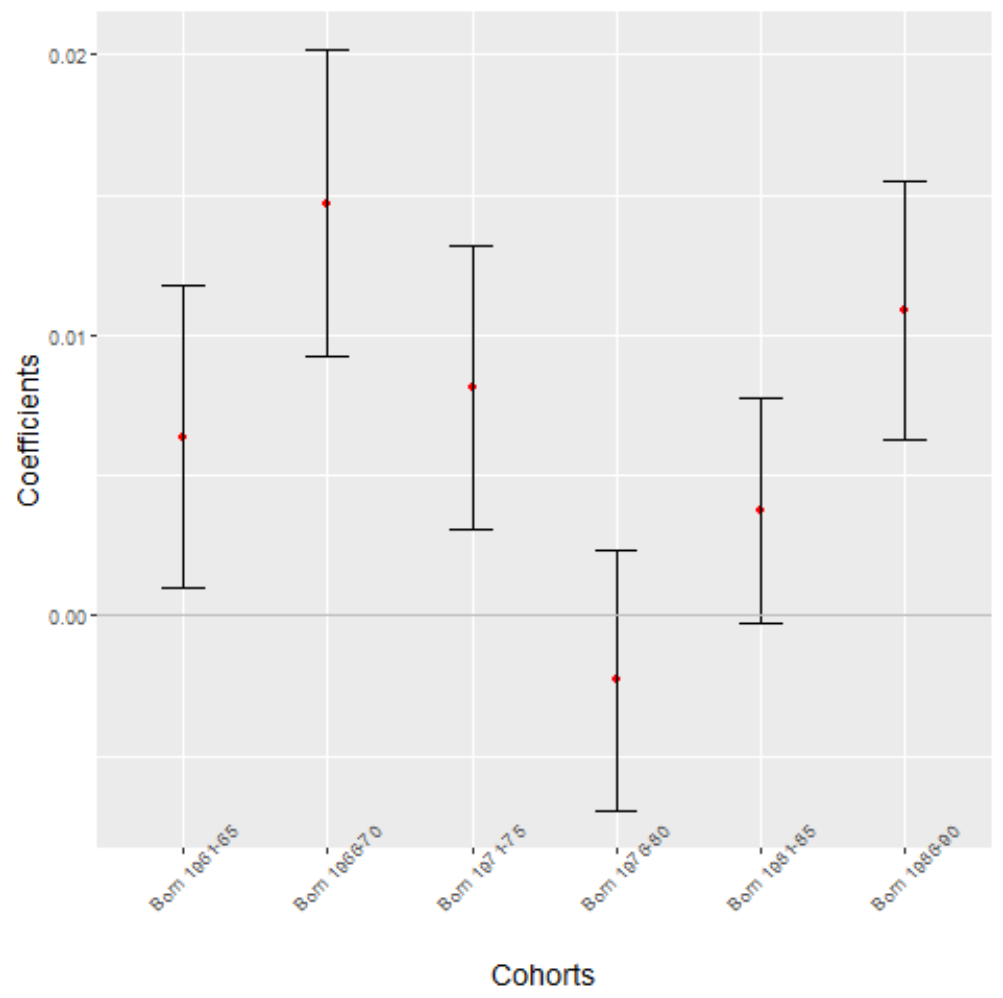

Figure 19: IV estimates of $\hat{\beta}$ 's from $(\star \star)$, for completion of primary school.

I find that these results are consistent with the reduced form estimates above, wherein communal violence closer to the Yatra route may have displaced Muslims into ethnic enclaves, where Muslim children going to school after 1990 also achieved higher levels of primary education. This may be due to presence of role models from the same community in these 
ethnic enclaves. These role models in the neighbourhood may have enabled Muslims to achieve higher levels of early education. However, as described in Section 2.4, the exclusion restriction may be violated in the presence of unobservable inputs in the education production function if such inputs are also determined by distance of the city from Yatra.

I build upon previous work in the literature to argue that unobservable inputs (like political environment) in the education production function (those that are correlated with the instrument) have an effect that is diametrically opposed to that of segregation. First, notice that Blakeslee (2018) finds significant electoral gains for the BJP in constituencies through which the Yatra passed. He finds a 6 percentage point increase in the party's vote share, and an 11 percentage point increase in their probability of victory in elections. Similarly, Iyer and Shrivastava (2015) demonstrates a 5 percentage points increase in the vote share of the BJP associated with exogenous variation in Hindu-Muslim riots. So, it is clear that the instrument is associated with electoral gains for the Hindu nationalist BJP.

While communal riots cause much damage to life and property of Muslims, my second observation deals with worsening (or lack of improvement) in employment, consumption and education outcomes of Muslims in BJP ruled constituencies (Mitul, 2020). Farooqui (2020) contends that the rise of BJP in the Indian political arena has grossly aggravated the underrepresentation of Muslims in politics, and this may be associated with worsening provision of public goods for this community. That is to say, unobservable political climate closer to the Yatra route must necessarily correlate with Muslim education outcomes negatively, as the communal riots in these areas may have caused greater harm to Muslim life and property (direct channel) or led to electoral gains for BJP (indirect channel), which could not have improved Muslim education outcomes.

Additionally, I have provided evidence in Figure 8 that household consumption for Muslims is not significantly different by treatment, pre or post- Yatra. Then it must be the case that $\lambda \leq 0$. However, notice in Figure 19 IV estimates for attainment of primary education, for cohorts born between 1981-90, imply that

$$
\delta+u^{\prime} \cdot \lambda>0
$$

This discussion suggests that since $u>0$ and $\lambda \leq 0$, (8) implies that $\delta>0$. That is to 
say, I can draw upon existing literature to make assumptions that enable me to conclude that the causal effect of segregated neighbourhoods on early education outcomes of Muslims is positive. In this way, I have correctly identified the direction of the causal effect of segregation on education outcomes, while relaxing the exclusion restriction.

Segregated Muslim neighbourhoods may be correlated with higher community spending on primary schools, in ways that improve school quality. This may be true, as more segregated cities also harbour a higher number of Muslim enterprises. However, this does not explain why I only see the effects in early education outcomes. A more convincing story, that is harder to test empirically, is given by the formation of Strong Ties within the community (Granovetter, 1973), as opposed to a larger number of Weak Ties outside the community.

These results, therefore, build on previous work evaluating positive neighbourhood effects on human capital formation of Muslims, who are likely to live in enclaves populated by other Muslim households (Geruso and Spears, 2018) in Indian cities. Strong within-community ties seem like the most plausible explanation of my results, which are very surprising and antithetical to research that finds negative effects of racial segregation on long term outcomes of Black men in the US (Chetty and Hendren, 2018).

This is supported by qualitative evidence in Jaffrelot and Gayer (2012), who claim that residents of Muslim enclaves, segregated by communal violence in Gujarat, eventually achieved higher socio-economic status, despite the conspicuously absent public provision of welfare for Muslims. This is because community links are very tightly knit in the aftermath of violence, as members support each other to rebuild businesses and incomes. While violence targeted at a community may strengthen already existing ties, the long term effects on the strength of these ties as well as identity formation is an open empirical question.

An investigation into the persistence of these ties across generations is beyond the scope of this paper, but it is plausible that Muslims may be investing in forming Strong Ties, from a sense of fear and loss. At the same time, they may not be formulating as many Weak Ties outside their community, which may be required to secure a position in institutions of higher learning. The absence of Weak Ties is a story that is consistent with underrepresentation of Muslims in political institutions, which further weakens their position to lobby for affirmative action in higher education and government jobs (Alam, 2010). Hence, 
this may explain the statistically insignificant neighbourhood effects on college education attainment for Muslims.

While I cannot observe discrimination against Muslims, at the level of secondary and tertiary education, it is very likely to be driving the results for secondary and tertiary education attainment among Muslims (Basant, 2012). This is still consistent with the story above, if $\mathrm{I}$ interpret discrimination as a consequence ${ }^{19}$ of the absence of weak ties outside the community.

\section{Additional Robustness Checks}

In this Section, I perform some additional robustness checks to strengthen my analysis of Muslim education outcomes with respect to distance of cities from Yatra route, as well as segregation along religious lines.

\subsection{Heterogeneous Effects of Muslim Population Share}

Firstly, I seek to understand how the treatment effects differ by proportion of Muslim population. That is to say, I estimate the heterogeneous effects of Muslim population in a city on the education outcomes of Muslims, by Yatra distance. I proxy for Muslim share of population by the proportion of Muslim owned enterprises in a city, calculated using the Sixth Economic Census (2013).

\footnotetext{
${ }^{19}$ Discrimination could co-vary inversely with the number of weak ties outside the community. Here, I am not taking a position on the direction of causality.
} 


\begin{tabular}{|c|c|c|}
\hline & (1) & $(2)$ \\
\hline & Born 1981-85 & Born 1986-90 \\
\hline \multicolumn{3}{|l|}{ Illiteracy Level } \\
\hline Yatra distance $\times$ Muslim $\times$ & 0.0000161 & 0.0000198 \\
\hline Muslim Enterprise Share & $(0.00000765)$ & $(0.00000771)$ \\
\hline Muslim $\times$ & -0.00310 & -0.00340 \\
\hline Muslim Enterprise Share & $(0.000872)$ & $(0.000894)$ \\
\hline \multicolumn{3}{|l|}{ Primary School } \\
\hline Yatra distance $\times$ Muslim $\times$ & -0.0000243 & -0.0000201 \\
\hline Muslim Enterprise Share & $(0.00000924)$ & $(0.00000962)$ \\
\hline Muslim $\times$ & 0.00365 & 0.00350 \\
\hline Muslim Enterprise Share & $(0.00105)$ & $(0.00112)$ \\
\hline \multicolumn{3}{|l|}{ Secondary School } \\
\hline Yatra distance $\times$ Muslim $\times$ & -0.00000724 & -0.0000153 \\
\hline Muslim Enterprise Share & $(0.0000152)$ & $(0.0000153)$ \\
\hline Muslim $\times$ & 0.000679 & -0.000213 \\
\hline Muslim Enterprise Share & $(0.00176)$ & $(0.00175)$ \\
\hline \multicolumn{3}{|l|}{ College } \\
\hline Yatra distance $\times$ Muslim $\times$ & -0.0000297 & -0.0000642 \\
\hline Muslim Enterprise Share & $(0.0000224)$ & $(0.0000220)$ \\
\hline Muslim $\times$ & 0.00298 & 0.00574 \\
\hline Muslim Enterprise Share & $(0.00256)$ & $(0.00246)$ \\
\hline
\end{tabular}

Standard errors in parentheses

Table 6: Heterogeneous treatment effects ${ }^{4}$ by share of Muslim enterprises in a city. 
The treatment effects for early education (Table 6) are still significant and have the same sign as in Figure 13. Additionally, it seems that cities with a high share of Muslim owned enterprises seem to improve primary as well as tertiary education outcomes for Muslims. This could be on account of presence of role models, or higher community funding for primary schools in cities with a higher share of Muslim enterprises. At any rate, this provides some evidence of positive neighbourhood effects for Muslims, consistent with the conclusions in Geruso and Spears (2018).

\subsection{Migration}

It is conceivable that in the aftermath of the violence, some Muslim families migrated to different cities, instead of safer locations in the same city. I therefore, take into account migration by controlling for difference in Muslim population in the cities between 1987 and 2012.

I estimate (2) controlling for difference in Muslim population, and find that the relationship between Muslim education attainment and the treatment still remains statistically significant for the relevant cohort, with the same signs as before. Figure 20 demonstrates this for primary education attainment. 


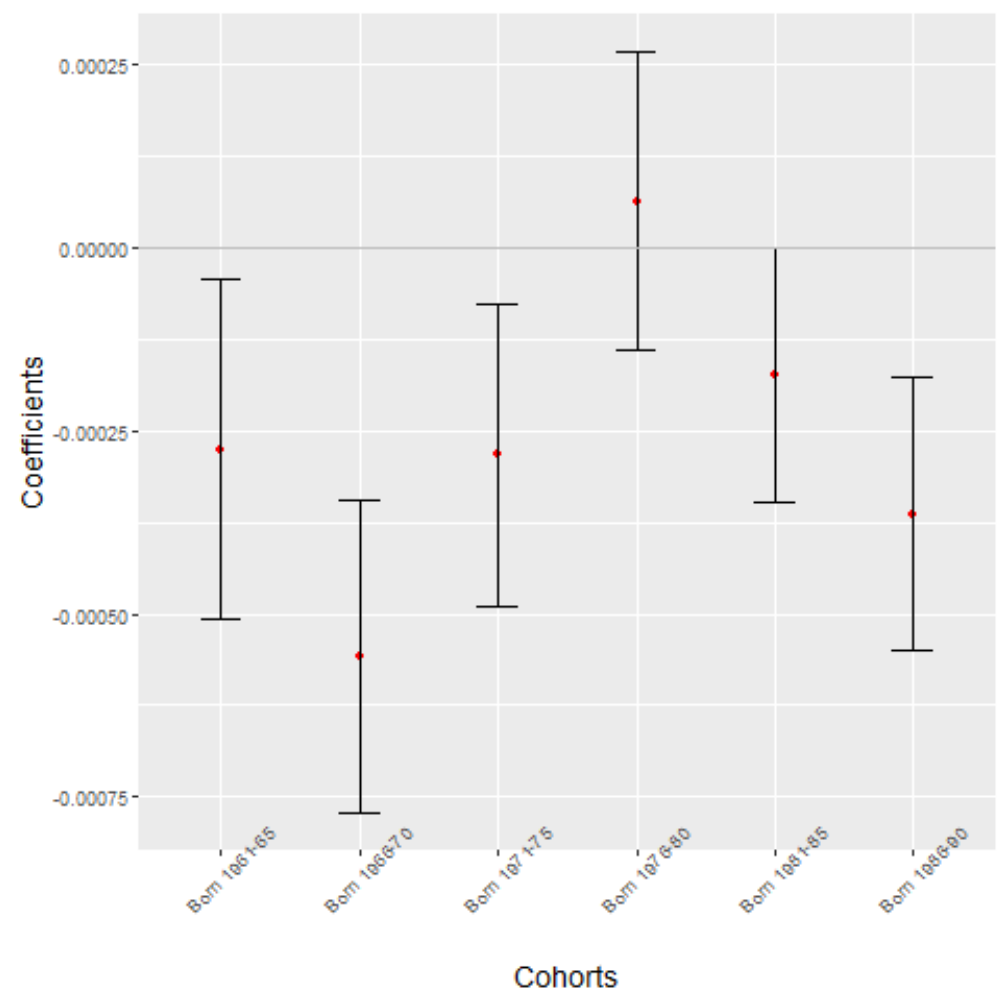

Figure 20: $\hat{\beta}$ 's estimated from (2), for completion of primary school after controlling for difference in Muslim population.

I provide corresponding estimates for illiteracy levels, secondary and college education in Figures A.14, A.15, and A.16, respectively. I draw the same conclusions as above.

\subsection{Treatment Effects on Untreated Groups}

\subsubsection{Yatra and Scheduled Castes}

Adukia et al. (2019) and Bharathi et al. (2018) document caste-based residential segregation in various Indian cities. I check if the treatment affects education outcomes of Scheduled Castes differently, where this group is considered to be untreated. In Figure 21, I observe parallel trends in SC and non-SC primary education attainment, with respect to distance from Yatra route. 


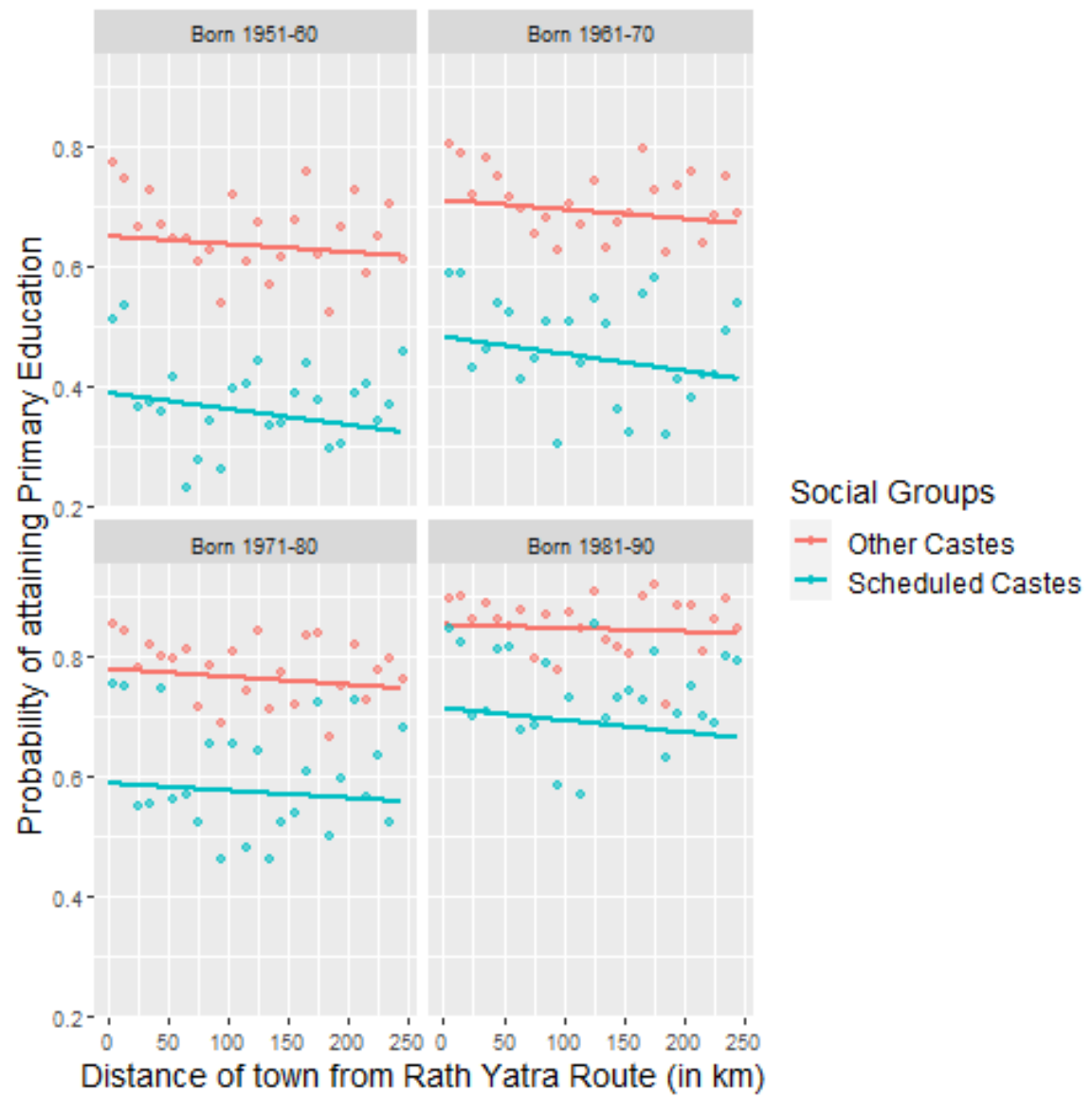

Figure 21: Relationship between caste-based segregation measure (dissimilarity index for scheduled caster $\times 100)$ and distance from Yatra route in kilometres.

Taken together, Figures 18 and 21 provide evidence that segregation is the channel associated with better early education outcomes for Muslims in India.

\subsubsection{States unaffected by Yatra}

As a final placebo test, I check if the first stage relationship between distance from Yatra route and dissimilarity index (measuring community/ religion based segregation) holds for states where the Ram Rath Yatra campaign did not enter. In Figure 22, I do not find statistically significant correlation between the treatment and segregation in these states. 


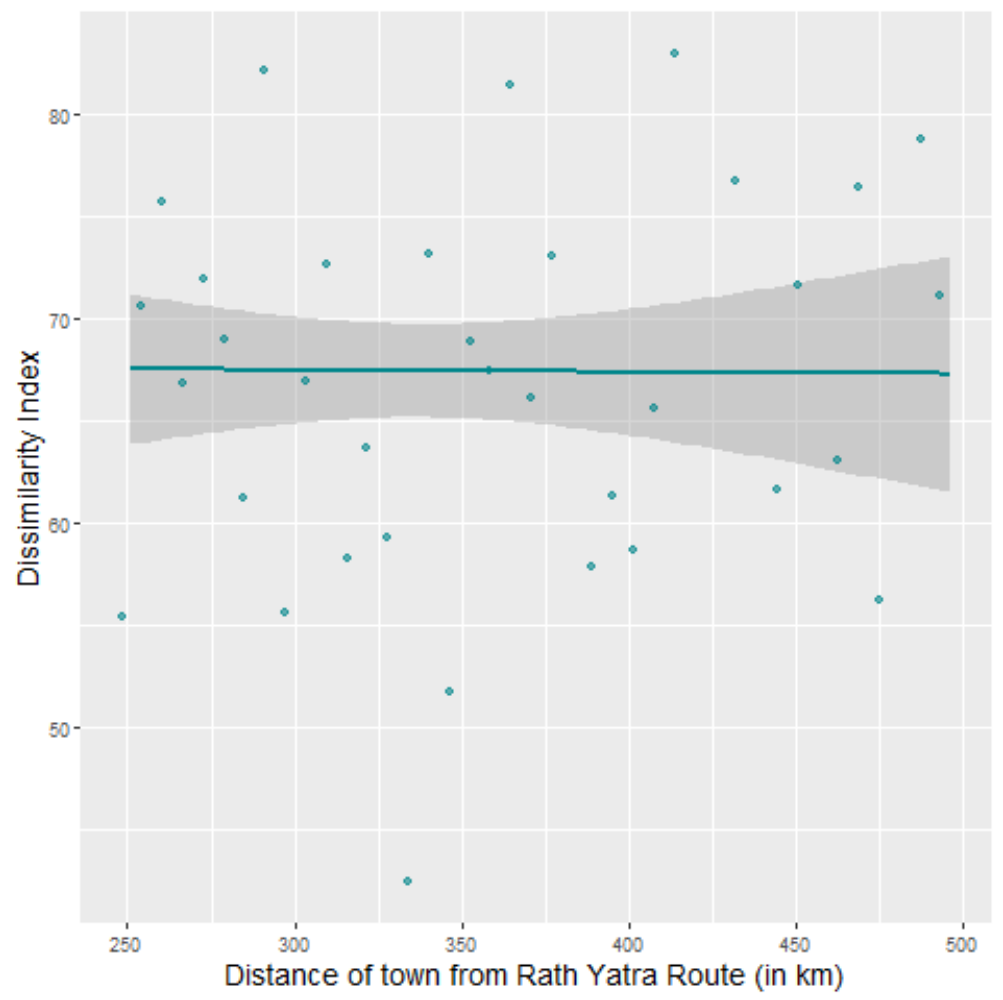

Figure 22: Relationship between segregation measure (dissimilarity index $\times 100$ ) and distance from Yatra route in kilometres, for states that did not witness the Yatra campaign.

Therefore, I do not find any spurious correlation in states that were not exposed to this campaign. I only consider cities within 250 to 500 kilometre range in these states, to avoid capturing spillovers to cities close to the Yatra states.

\section{Conclusion}

In this paper, I evaluated the long-term impacts of a violent event of great political significance in contemporary India. Surprisingly, I found that Muslims perform better in cities that were more susceptible to communal violence in terms of early education outcomes, whereas overall educational mobility of Muslims has been declining in the country Asher et al. (2018). I also found that cities that were closer to the route of the Ram Rath Yatra 
are more segregated than cities farther away.

Based on the reduced form estimates, I isolated the causal impact of neighbourhood effects on Muslim education outcomes, using distance from Yatra route as an instrument. I found that higher dissimilarity index leads to better early education outcomes for Muslims. I also demonstrated that the direction of the effect remains unchanged under less restrictive assumptions on the validity of the instrument.

I discuss various mechanisms through which neighbourhood effects could improve education outcomes. I stipulate that Muslim enclaves may witness stronger ties within the community in the aftermath of communal violence. In this process, Muslims may not be forming weak ties outside the community. This affects their ability to bargain for positions in higher education institutions.

My findings open various avenues for future research. Firstly, it is worth enquiring how Muslim parents make schooling decisions for their children in cities, as we need a better understanding of school choice mechanisms in urban India. Secondly, the available data limits our understanding of inputs that produce quality education in urban schools. This has serious policy implications in Developing countries.

Thirdly, I have only employed cross-sectional variation in segregation. Temporal variation in residential segregation would enable estimation of neighbourhood effects on education outcomes for various disadvantaged social groups. Adukia et al. (2019) also highlight that research employing better measures of residential segregation, than the one employed here, would also bring valuable insights.

Finally, research backed by data on social networks, in segregated and integrated neighbourhoods, would provide a concrete understanding of the mechanisms through which the choice of residential neighbourhoods impacts educational outcomes of historically disadvantaged social groups.

This paper contributes to existing literature on inter-group inequality in Developing countries by demonstrating the effect of communal violence on education outcomes of historically disadvantaged groups. I have also highlighted channels through which communal violence drives group education outcomes, and a deeper investigation into these mechanisms is a 
subject for future research. 


\section{References}

A. Abdulkadiroğlu, J. Angrist, and P. Pathak. The elite illusion: Achievement effects at boston and new york exam schools. Econometrica, 82(1):137-196, 2014.

A. Adukia, S. Asher, P. Novosad, and B. Tan. Residential segregation in urban india. Working Paper, September 2019. URL https://www.isid.ac.in/ epu/acegd2019/papers/ SamAsher.pdf.

M. S. Alam. Social exclusion of muslims in india and deficient debates about affirmative action: Suggestions for a new approach. South Asia Research, 30(1):43-65, 2010.

A. Alesina, S. Michalopoulos, and E. Papaioannou. Ethnic inequality. Journal of Political Economy, 124(2):428-488, 2016.

A. Alesina, S. Hohmann, S. Michalopoulos, and E. Papaioannou. Religion and educational mobility in africa. Technical report, National Bureau of Economic Research, 2020.

S. Asher, P. Novosad, and C. Rafkin. Intergenerational mobility in india: Estimates from new methods and administrative data. Working Paper, September 2018. URL http: //www.dartmouth.edu/ novosad/anr-india-mobility.pdf.

S. Asher, T. Lunt, R. Matsuura, and P. Novosad. The Socioeconomic High-resolution RuralUrban Geographic Dataset on India (SHRUG). Working paper, 2019.

K. Balagopal. This anti-mandal mania. Economic and political weekly, pages 2231-2234, 1990.

R. Basant. Education and employment among muslims in india: An analysis of patterns and trends. 2012.

S. Bhalotra, C. Valente, and A. Van Soest. The puzzle of muslim advantage in child survival in india. Journal of Health Economics, 29(2):191-204, 2010.

N. Bharathi, D. V. Malghan, and A. Rahman. Isolated by caste: Neighbourhood-scale residential segregation in indian metros. IIM Bangalore Research Paper, (572), 2018.

D. Blakeslee. The Rath Yatra effect: Hindu nationalist propaganda and the rise of the bjp. Working Paper, June 2018. URL http://www.davidsblakeslee.net/uploads/1/1/4/ 4/114438143/blakeslee_hindu_nationalist_propaganda_and_the_bjp__2018_.pdf. 
R. Chetty and N. Hendren. The impacts of neighborhoods on intergenerational mobility i: Childhood exposure effects. The Quarterly Journal of Economics, 133(3):1107-1162, 2018.

R. Chetty, N. Hendren, P. Kline, and E. Saez. Where is the land of opportunity? the geography of intergenerational mobility in the united states. The Quarterly Journal of Economics, 129(4):1553-1623, 2014.

A. A. Engineer. The bloody trail: Ramjanmabhoomi and communal violence in up. Economic and Political Weekly, pages 155-159, 1991.

J. Esteban and D. Ray. Linking conflict to inequality and polarization. American Economic Review, 101(4):1345-74, 2011.

A. Farooqui. Political representation of a minority: Muslim representation in contemporary india. India Review, 19(2):153-175, 2020.

E. Field, M. Levinson, R. Pande, and S. Visaria. Segregation, rent control, and riots: The economics of religious conflict in an indian city. American Economic Review, 98(2):505-10, 2008.

M. Geruso and D. Spears. Neighborhood sanitation and infant mortality. American Economic Journal: Applied Economics, 10(2):125-62, 2018.

S. Gopal, R. Thapar, B. Chandra, S. Bhattacharya, S. Jaiswal, H. Mukhia, K. Panikkar, R. Champakalakshmi, S. Saberwal, B. Chattopadhyaya, et al. The political abuse of history: Babri masjid-rama janmabhumi dispute. Social scientist, pages 76-81, 1990.

M. S. Granovetter. The strength of weak ties. American journal of sociology, 78(6):1360$1380,1973$.

M. Greenstone and R. Hanna. Environmental regulations, air and water pollution, and infant mortality in india. American Economic Review, 104(10):3038-72, 2014.

M. Harari. Cities in bad shape: Urban geometry in india. American Economic Review, 110 (8):2377-2421, 2020. 
K. Hirano and G. W. Imbens. The propensity score with continuous treatments. Applied Bayesian modeling and causal inference from incomplete-data perspectives, 226164:73-84, 2004.

S. Iyer and A. Shrivastava. Religious riots and electoral politics in india. 2015.

C. Jaffrelot. Religion, caste, and politics in India. Primus Books, 2010.

C. Jaffrelot and L. Gayer. Muslims in Indian cities: Trajectories of marginalisation. Columbia University Press, 2012.

C. Jaffrelot and A. Kalaiyarasan. On socio-economic indicators, muslim youth fare worse than scs and obcs. Indian Express, November 2019. URL https://indianexpress.com/article/opinion/columns/ muslim-community-youth-india-marginalisation-6096881/.

D. S. Massey. American apartheid: Segregation and the making of the american underclass. American Journal of Sociology, 96(2):329-357, 1990.

E. Meyersson. Islamic rule and the empowerment of the poor and pious. Econometrica, 82 (1):229-269, 2014.

L. Mishra. Temple rerun: Tracing ram rath yatra, 25 years later. Indian Express, September 2015. URL https://indianexpress.com/article/opinion/columns/ muslim-community-youth-india-marginalisation-6096881/.

A. Mitra and D. Ray. Implications of an economic theory of conflict: Hindu-muslim violence in india. Journal of Political Economy, 122, 4:719-765, August 2014.

S. Mitul. Essays on Electoral Democracy and Development. IIMA Institutional Repository, Thesis and Dissertations, 2020. URL http://vslir.iima.ac.in:8080/xmlui/handle/ $11718 / 23142$.

Ministry of Statistics and Program Implementation (Government of India). Town directory, population census, 2011.

Ministry of Statistics and Program Implementation (Government of India). Sixth economic census, 2013. 
Ministry of Rural Development and Ministry of Housing and Urban Poverty Alleviation. Socio-economic and caste census, 2011.

National Sample Survey Organization, Ministry of Statistics and Program Implementation (Government of India). Employment and unemployment survey: Nss 43rd round, schedule 10, july 1987 - june 1988, 1988.

National Sample Survey Organization, Ministry of Statistics and Program Implementation (Government of India). Employment and unemployment : Nss 68th round, schedule 10, july 2011- june 2012, 2012.

Z. Pathak and R. S. Rajan. Shahbano. Signs: Journal of Women in Culture and Society, 14(3):558-582, 1989.

R. Prasad. Urban Local Self-government in India. Mittal Publications, 2006.

O. Rashid and K. Venkataraman. When did the dispute over ram janmabhoomi start, and why did it take so long for a resolution? The Hindu, 2019. URL https://www.thehindu.com/news/national/ when-did-the-dispute-over-ram-janmabhoomi-start-and-why-did-it-take-so-long-for-a-resolution/ article29933375.ece.

Reserve Bank of India. Handbook of statistics on indian economy, consumer price indexannual average, 2018. URL https://m.rbi.org.in/scripts/PublicationsView .aspx? id $=18503$.

J. M. Robins, M. A. Hernan, and B. Brumback. Marginal structural models and causal inference in epidemiology, 2000.

NASA Socioeconomic Data and Applications Center, Center for International Earth Science Information Network. Global rural-urban mapping project, version 1, 2011. URL http: //sedac.ciesin.columbia.edu/data/collection/grump-v1.

R. Sethi and R. Somanathan. Group identity and social mobility in india. In Conference on Social Policy in India, University of Warwick, July, pages 2-3. Citeseer, 2010.

R. Somanathan and H. Kumar. Mapping indian districts across census years, 1971-2001. Technical report, 2009. 
R. Susewind. Muslims in indian cities: Degrees of segregation and the elusive ghetto. Environment and Planning A, 49(6):1286-1307, 2017.

A. Varshney and S. Wilkinson. Varshney-wilkinson dataset on hindu-muslim violence in india, 1950-1995, version 2. Ann Arbor, MI: Inter-university Consortium for Political and Social Research, 2006. URL https://doi.org/10.3886/ICPSR04342.v1.

L. Yadav. Why and how $\mathrm{i}$ arrested $\mathrm{lk}$ advani. NDTV, December 2017. URL https://www.ndtv.com/blog/ lalu-yadav-on-why-and-how-he-arrested-lk-advani-on-october-23-1990-1784734. 


\section{Appendix A: Graphs}

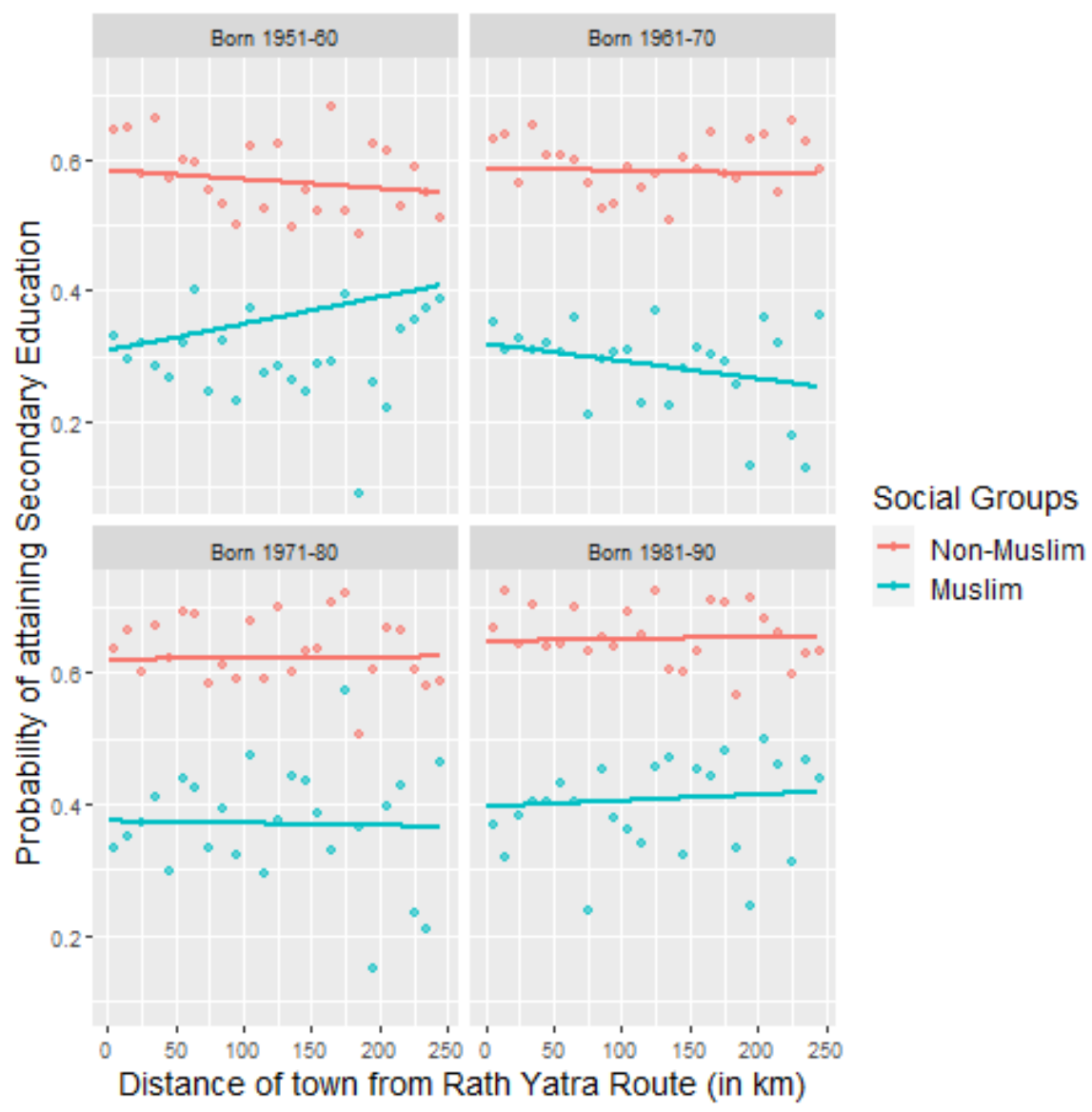

Figure A.1: Probability of attaining secondary education by religion, cohort, and distance from Yatra 


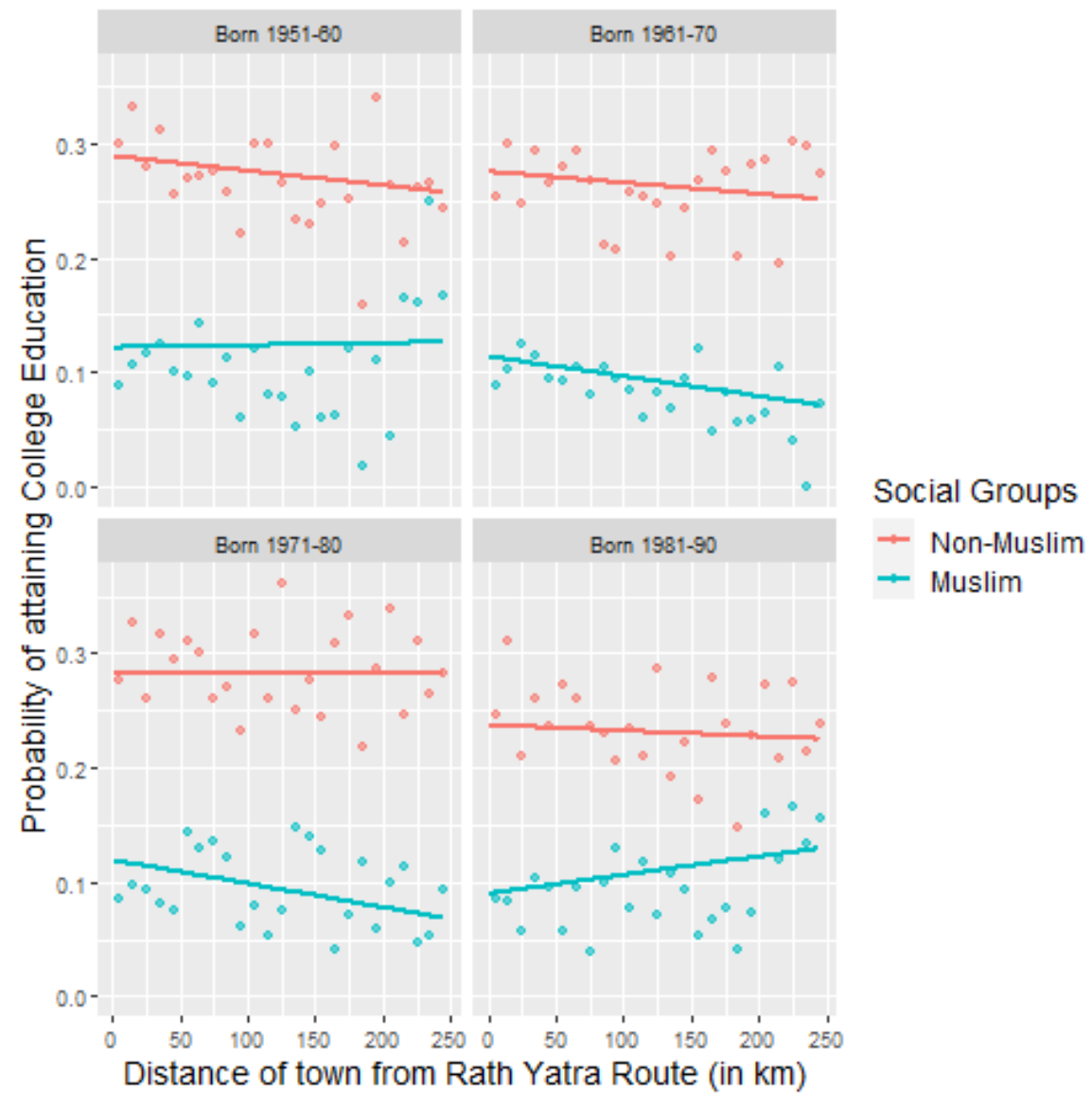

Figure A.2: Probability of attaining college education by religion, cohort, and distance from Yatra 


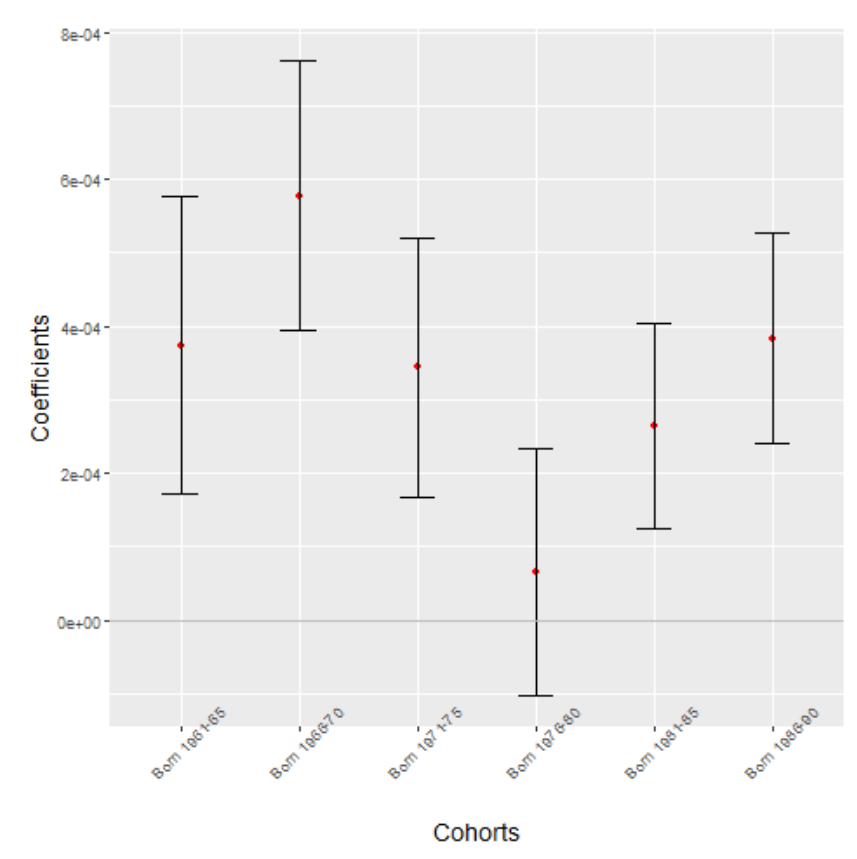

Figure A.3: $\hat{\beta}$ 's estimated from (2), for illiteracy levels

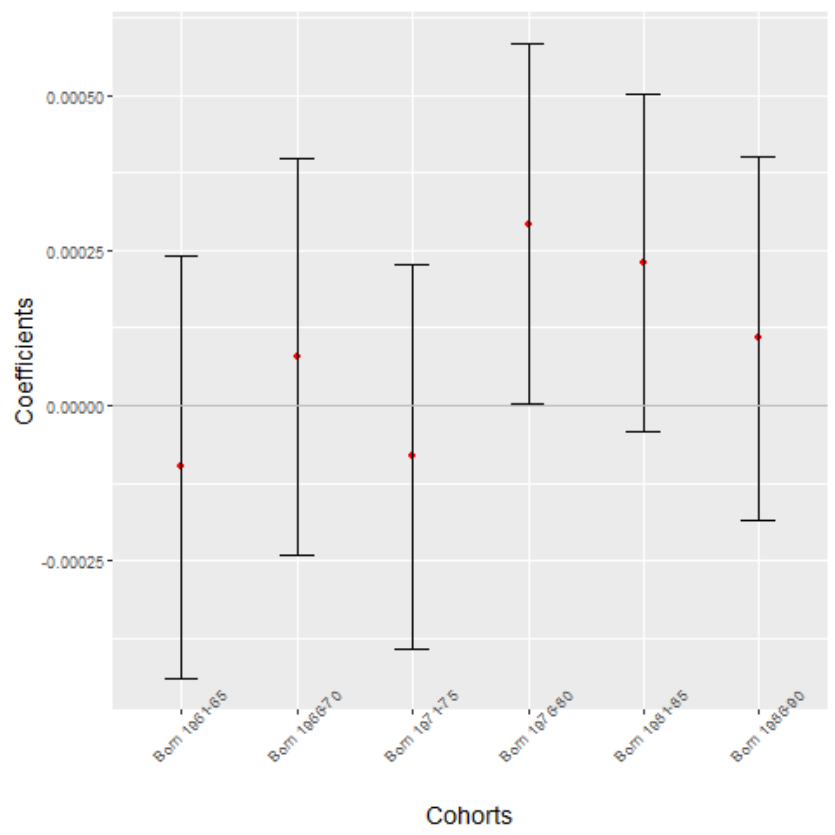

Figure A.4: $\hat{\beta}$ 's estimated from (2), for completion of secondary school 


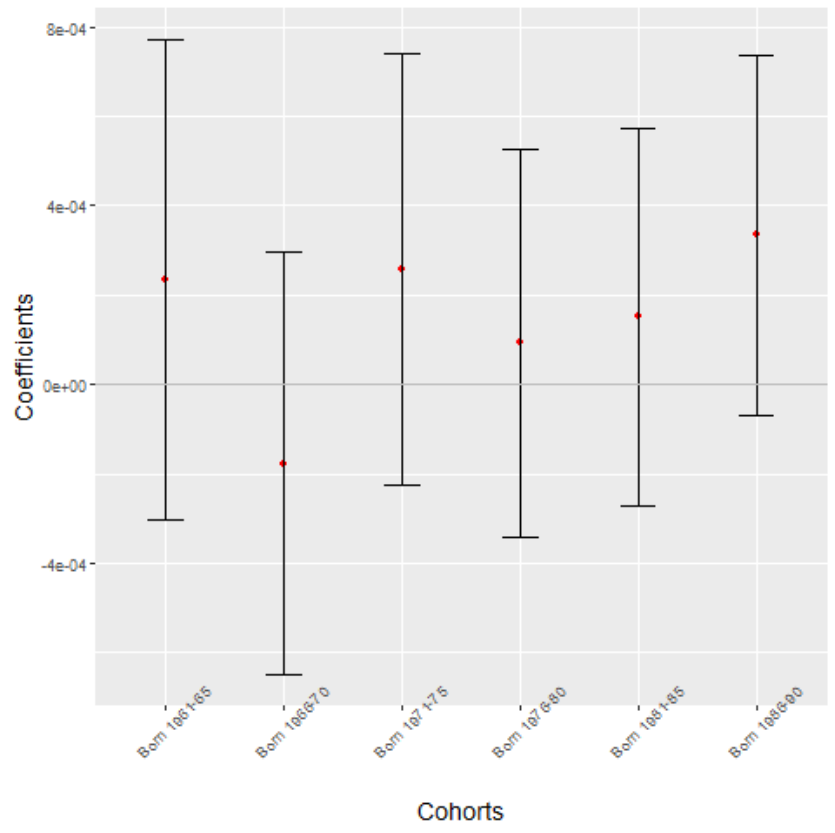

Figure A.5: $\hat{\beta}$ 's estimated from (2), for attainment of college education 


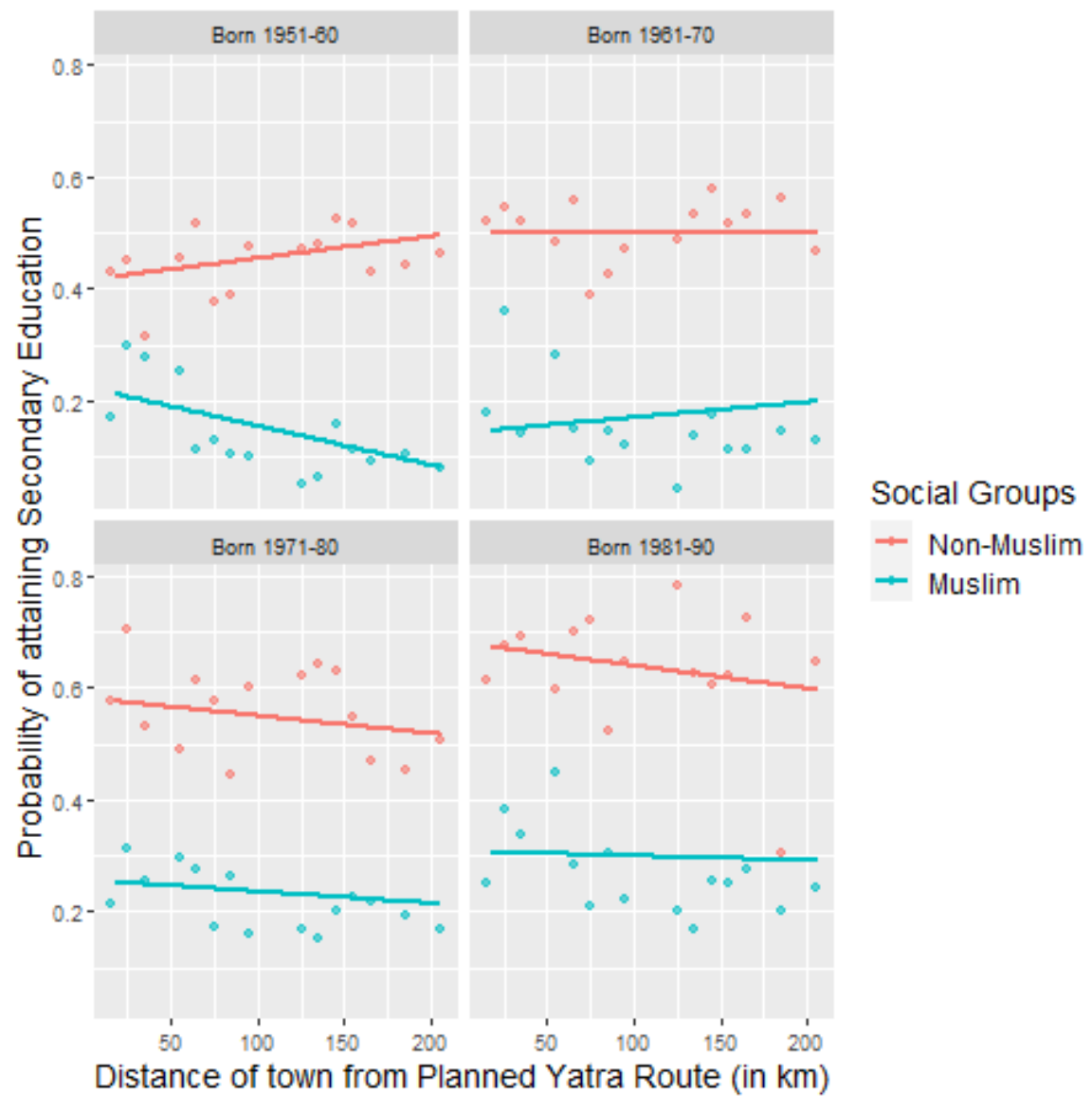

Figure A.6: Probability of attaining secondary education by religion, cohort, and distance from placebo Yatra. 


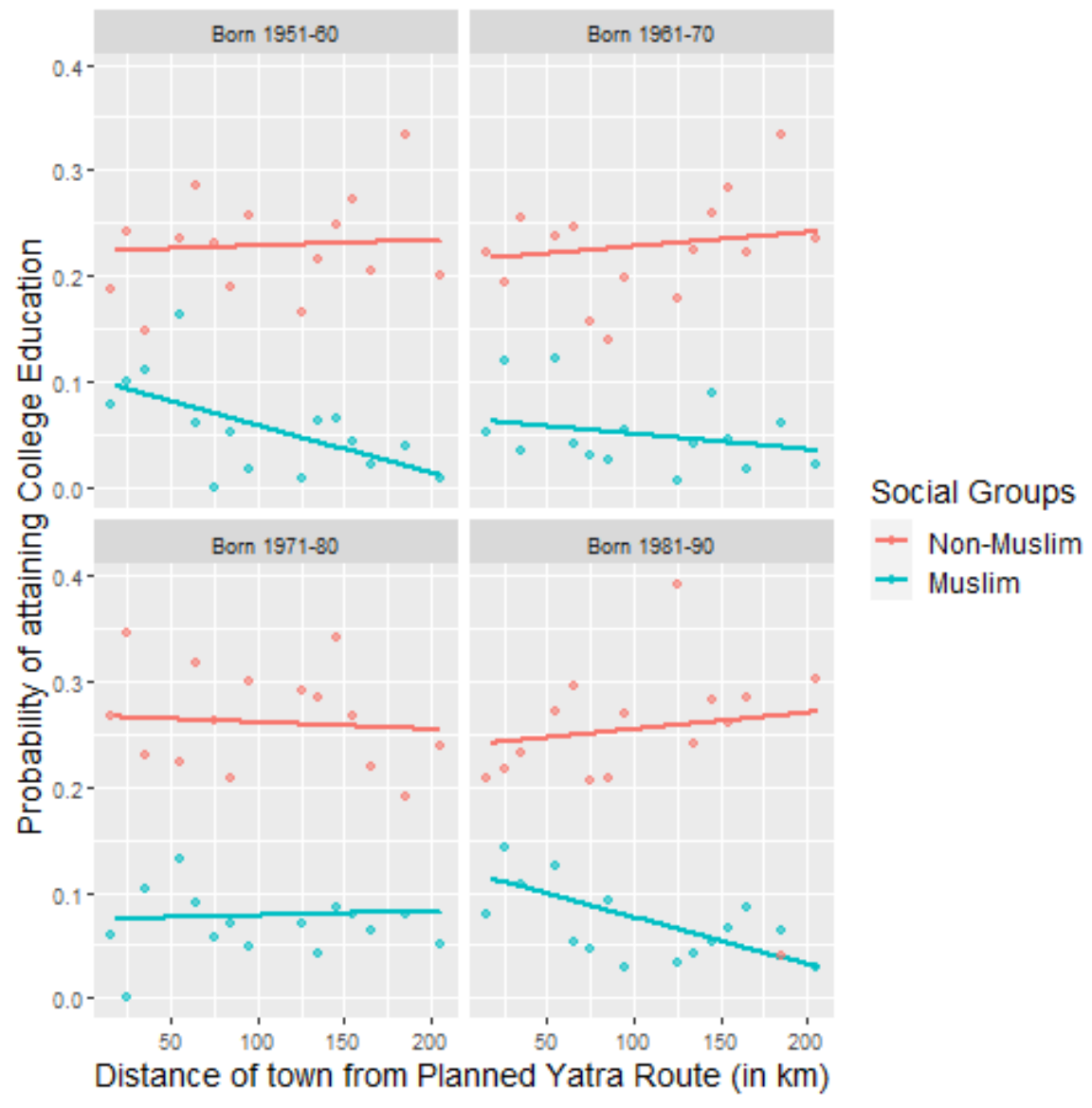

Figure A.7: Probability of attaining college education by religion, cohort, and distance from placebo Yatra. 


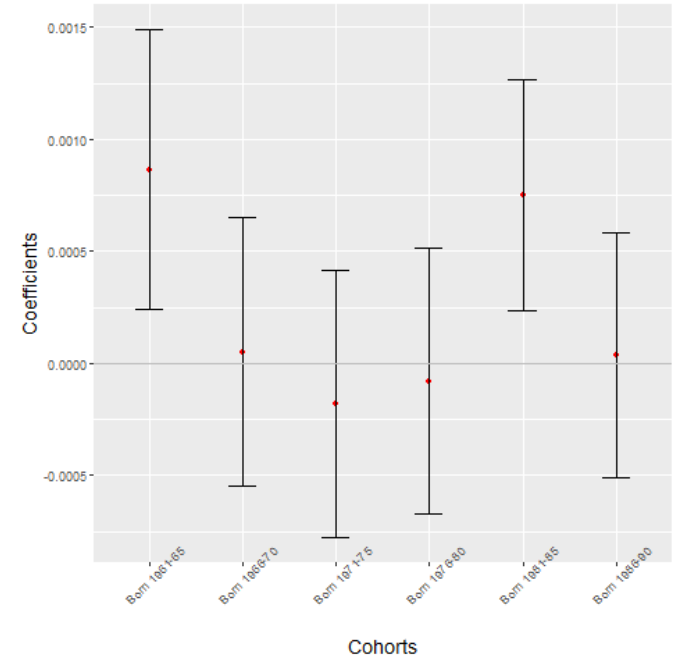

Figure A.8: $\hat{\beta}$ 's estimated from (3) with respect to placebo Yatra, for illiteracy levels

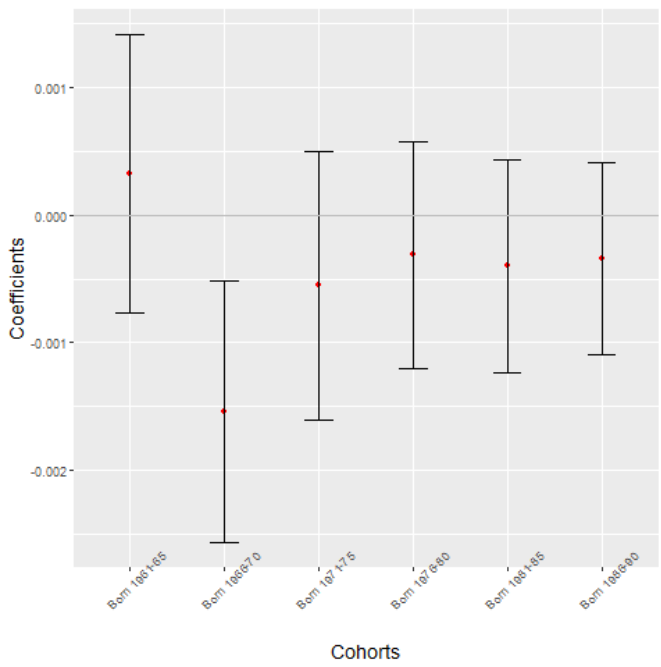

Figure A.9: $\hat{\beta}$ 's estimated from (3) with respect to placebo Yatra, for completion of secondary school. 


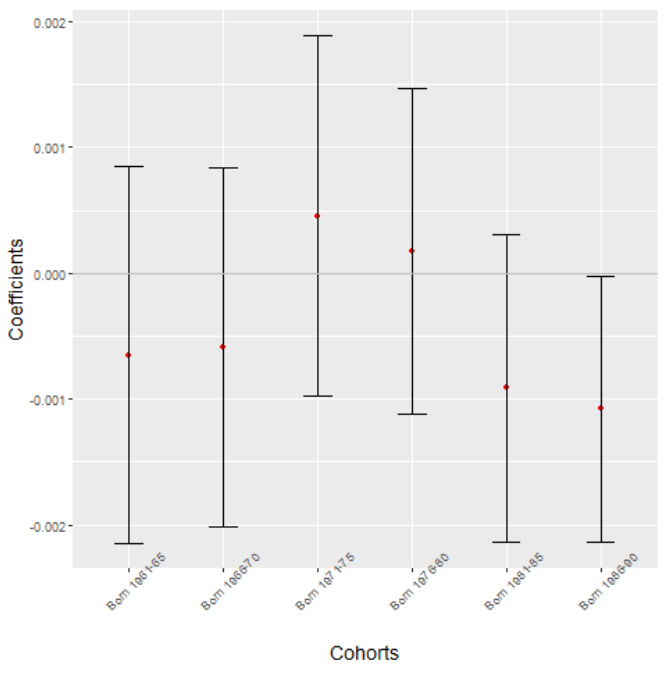

Figure A.10: $\hat{\beta}$ 's estimated from (3) with respect to placebo Yatra, for completion of primary school. 


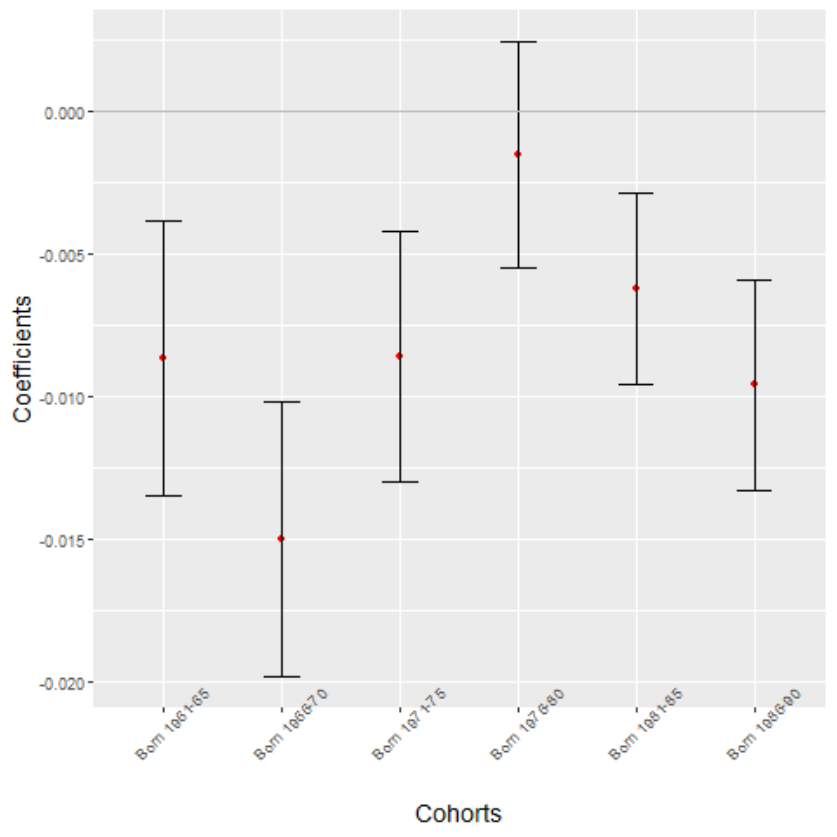

Figure A.11: IV estimates of $\hat{\beta}$ 's from ( $\star \star)$, for illiteracy levels.

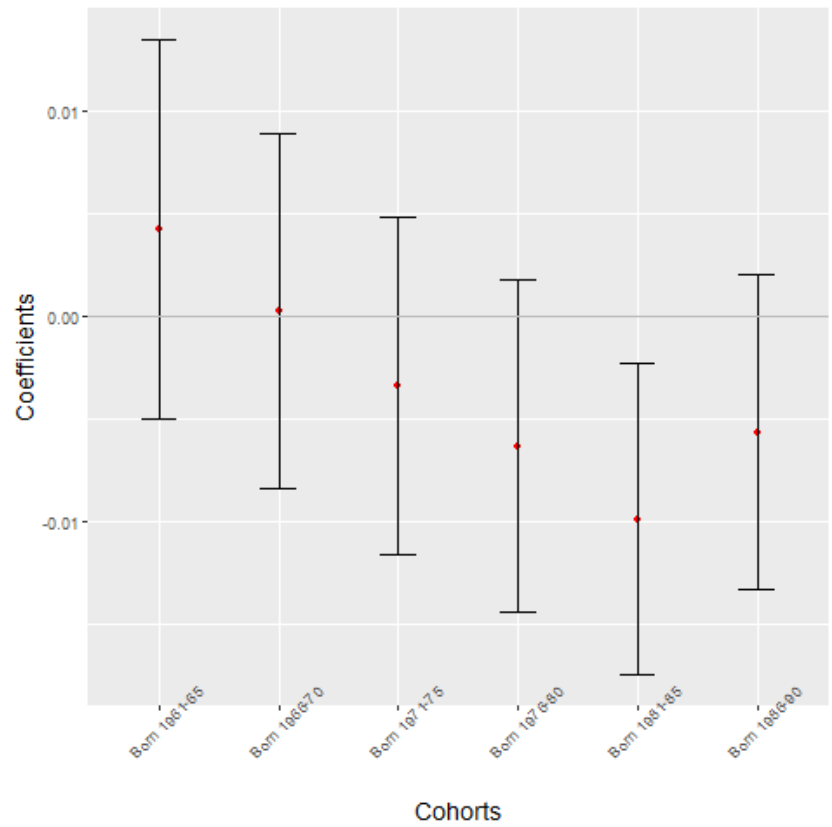

Figure A.12: IV estimates of $\hat{\beta}$ 's from $(\star \star)$, for completion of secondary school. 


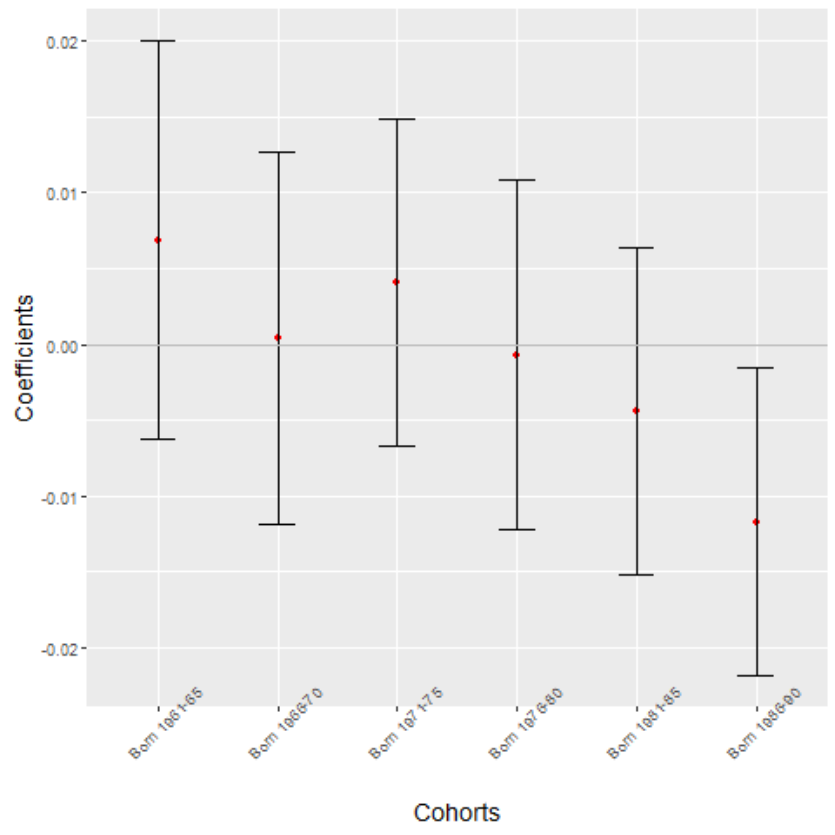

Figure A.13: IV estimates of $\hat{\beta}$ 's from $(\star \star)$, for completion of college

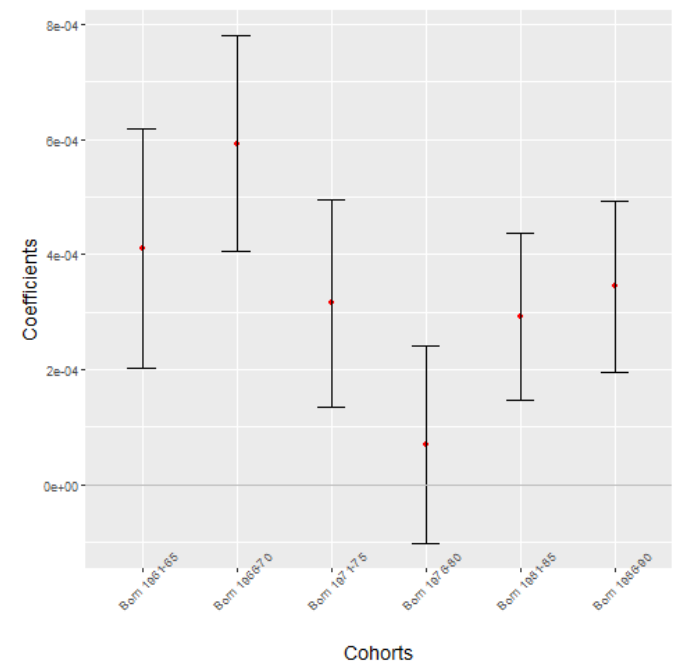

Figure A.14: $\hat{\beta}$ 's estimated from (2), for illiteracy levels after controlling for difference in Muslim population. 


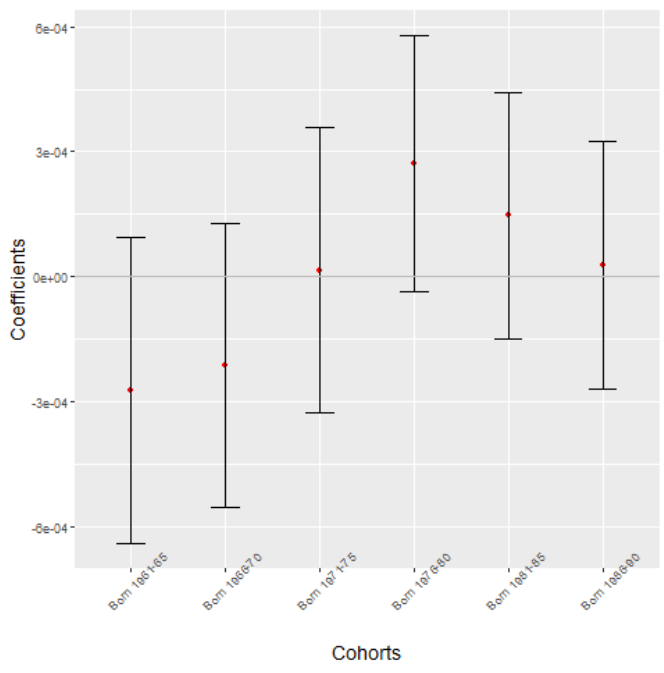

Figure A.15: $\hat{\beta}$ 's estimated from (2), for completion of secondary school after controlling for difference in Muslim population.

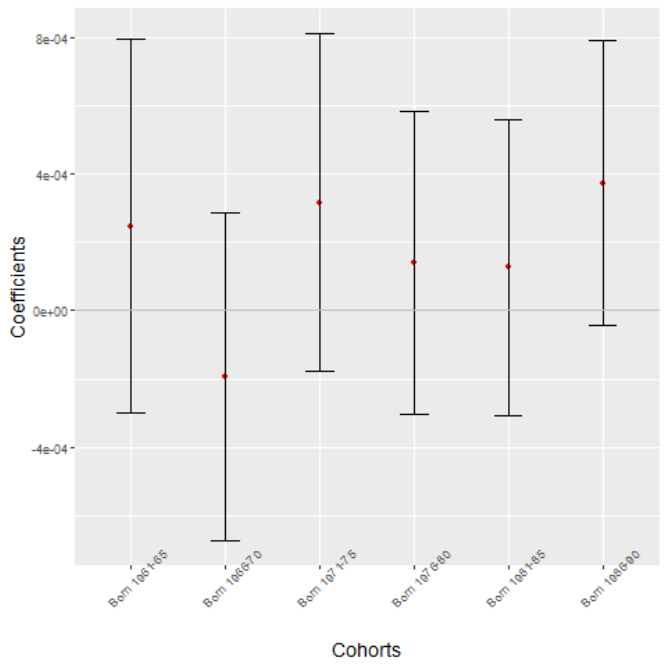

Figure A.16: $\hat{\beta}$ 's estimated from (2), for college education after controlling for difference in Muslim population. 


\section{Appendix B: Tables}

\begin{tabular}{lccc}
\hline \hline & $(1)$ & $(2)$ & $(3)$ \\
\hline Distance from Yatra (in km) & -.023836 & -0.0206 & \\
& $(0.0105)$ & $(0.0104)$ & \\
& & & \\
Log of Distance from Yatra & & & -1.832 \\
& & & $(0.706)$ \\
& & & \\
\hline Population Controls & NO & YES & NO \\
Muslim Enterprise Controls & NO & YES & NO \\
\hline$N$ & 177 & 177 & 177 \\
F & 4.181 & 5.112 & 6.729 \\
\hline \hline
\end{tabular}

Standard errors in parentheses

Table B.1: OLS estimates from regression of Segregation Measure (Dissimilarity Index $\times 100$ ) on Distance from Yatra, with city level controls 


\section{Section C: Concepts and Definitions}

\section{Dissimilarity Index}

Residential segregation, for some city $c$, is measured with the Dissimilarity Index (Massey, 1990):

$$
d_{c}=\frac{1}{2} \sum_{i}\left|\frac{m_{i c}}{M_{c}}-\frac{h_{i c}}{H_{c}}\right|
$$

where, $m_{i c}$ is the Muslim population in city $c$ in EB $i, M_{c}$ is the total population of Muslims in city $c, h_{i c}$ is the non-Muslim population in city $c$ in $\mathrm{EB} i$, and $H_{c}$ is the total population of non-Muslims in city $c$.

Essentially, the dissimilarity index captures evenness in the distribution of the two social groups across neighbourhoods that constitute a city. Its value ranges between 0 and 1, where the value of $d_{c}$ attains the maximum value when each neighbourhood has residents from only one group. On the other hand $d_{c}$ is at its miniumum when $\frac{m_{i c} / T_{c}}{M_{c} / T_{c}}=\frac{h_{i c} / T_{c}}{H_{c} / T_{c}}$ in all neighbourhoods $i$ in city $c$ where $T_{c}$ is the total population in the city. In other words, $d_{c}=0$ when proportion of each group in each neighbourhood equals the proportion of each group in the city, i.e.

$$
\frac{m_{i c} / T_{c}}{h_{i c} / T_{c}}=\frac{M_{c} / T_{c}}{H_{c} / T_{c}}
$$

